\title{
As Formações Santo Antônio do Bonito e Rocinha (Grupo Vazante, Minas Gerais): sedimentação gravitacional sin a pós-glacial e fosfogênese na transição Faixa Brasília-Cráton do São Francisco
}

\author{
The Santo Antônio do Bonito and Rocinha formations (Vazante Group, Minas Gerais): \\ syn to post-glacial gravitational sedimentation and phosphogenesis in the Brasilia \\ Belt-São Francisco Craton transition
}

\author{
Carla Sofia de Sousa Marques ${ }^{1}$ (D), Alexandre Uhlein² (D), Gabriel Jubé Uhlein² (D), Edinei Koester ${ }^{3}$ (D), \\ Eduardo Luís Carneiro de Oliveira ${ }^{1}$ (D) \\ ${ }^{1}$ Universidade Federal de Minas Gerais - UFMG, Instituto de Geociências, Programa de Pós-Graduação em Geologia, \\ Av. Antônio Carlos, 6.627, Campus Pampulha, CEP: 31270-901, Belo Horizonte, MG, BR (smarques085@gmail.com; \\ eduardo@jacutingamineral.com) \\ 2UFMG, Belo Horizonte, MG, BR (auhlein@gmail.com; guhlein@gmail.com) \\ ${ }^{3}$ Universidade Federal do Rio Grande do Sul - UFRGS, Porto Alegre, RS, BR (koester@ufrgs.br)
}

Recebido em 15 de novembro de 2019; aceito em 20 de maio de 2021

\begin{abstract}
Resumo
As Formações Santo Antônio do Bonito e Rocinha, unidades basais do Grupo Vazante, compreendem diamictitos, arenitos, pelitos e raros carbonatos, originados de uma sedimentação gravitacional subaquosa, formando um sistema deposicional de slope-apron. Na região estudada, ao leste da cidade de Coromandel (Minas Gerais), no Vale do Rio Santo Antônio do Bonito, procedeu-se a mapeamento geológico, análise de fácies sedimentares, estudos isotópicos e comparação entre fosforitos sedimentares visando análise estratigráfica regional. Os dados geocronológicos U-Pb em zircão detrítico indicam idade deposicional máxima neoproterozoica para ambas as formações (idade concordante mais jovem de $934 \pm 8 \mathrm{Ma}$ ), mas com proveniências ligeiramente diferentes entre as unidades. Dados isotópicos Sm-Nd mostram idades $\mathrm{T}_{\mathrm{DM}}$ e valores de $\varepsilon \mathrm{Nd}_{(\mathrm{t})}$ diferentes entre as duas unidades, sugerindo, também, mudança nas áreas fontes. Os dados Sm-Nd também mostram grande semelhança entre as Formações Santo Antônio do Bonito e Jequitaí, cujas idades $\mathrm{T}_{\mathrm{DM}}$ são Paleoproterozoicas, com valores entre 1,8 e 2,1 Ga. Dados isotópicos Sm-Nd mostram, também, grande diferença entre pelitos da Formação Rocinha e pelitos do Grupo Bambuí (Formação Serra de Santa Helena). De leste para oeste, uma sedimentação glacial (Formação Jequitaí) é retrabalhada por processos gravitacionais, passando para um sistema de slope-apron na margem do paleocontinente São Francisco (Formações Santo Antônio do Bonito e Rocinha). Os depósitos fosfáticos do Grupo Vazante, nomeados de depósitos Coromandel (basal), Rocinha e Lagamar (topo), são comparados e, então, relacionados a um grande evento transgressivo fosfogênico pós-glacial de possível idade ediacarana. Esse enriquecimento em fosfato ocorre em ritmitos (fosfoarenitos ricos em intraclastos com granulometria de areia fina/média, fluorapatitas e matriz criptocritalina), enriquecidos, posteriormente, por processos supergênicos, formando wavellita nas fraturas.
\end{abstract}

Palavras-chave: Neoproterozoico; Cunha clástica; Isótopos Sm-Nd; Glaciação; Fosforitos sedimentares.

\section{Abstract}

The Santo Antônio do Bonito and Rocinha formations, basal units of the Vazante Group, comprise diamictites, sandstones, pelites and rare carbonates, originated from a subaqueous gravitational sedimentation, composing a slope-apron depositional system. In the studied region, east of the city of Coromandel (Minas Gerais), in the Santo Antônio do Bonito River Valley, a regional stratigraphic analysis was conducted from geological mapping, sedimentary facies analysis, isotopic study and comparison between sedimentary phosphorites for regional stratigraphic analysis. Zircon U-Pb ages yield a maximum depositional age of $934 \pm 8 \mathrm{Ma}$, but with subtle provenance differences between both units. Sm-Nd isotopic data show contrasting $\mathrm{T}_{\mathrm{DM}}$ model ages and $\varepsilon \mathrm{Nd}_{(\mathrm{t})}$ values for the two units, also suggesting source area changes. Sm-Nd data also show great similarity between the Santo Antônio do Bonito Formation and the Jequitaí Formation (Bambuí Group), whose $\mathrm{T}_{\mathrm{DM}}$ ages are Paleoproterozoic, with values between 1.8 and $2.1 \mathrm{Ga}$. Sm-Nd data also show great difference between pelites from 
the Rocinha Formation and pelites from the Bambuí Group (Serra de Santa Helena Formation). From east to west, the glacial sediments (Jequitaí Formation) are reworked by gravitational processes, evolving to a slope-apron system in the margin of the São Francisco paleocontinent (Santo Antônio do Bonito and Rocinha Formations). The phosphatic deposits of the Vazante Group, named Coromandel (basal) and Rocinha and Lagamar (upper), are thus related to a major phosphogenetic transgressive event in a post-glacial context, probably during the Ediacaran. The phosphate enrichment occurs in rhythmites (phosphoarenites rich in intraclasts with fine/medium sand granulometry, fluorapatites and cryptocritaline matrix), later enriched by supergenic processes, forming wavellite in fractures.

Keywords: Neoproterozoic; Slope-apron; Sm-Nd Isotopes; Glaciation; Sedimentary Phosphorite.

\section{INTRODUÇÃO}

O Grupo Vazante representa uma sucessão carbonática-siliciclástica depositada no Meso-Neoproterozoico, localizado na borda leste da Faixa Brasília, na transição com o Cráton do São Francisco. Ocorre nessa região um conjunto de dobras e falhas reversas formando um sistema de deformação epidérmica, em que uma imbricação complexa de rochas do embasamento e supracrustais foi promovida pela Orogenia Brasiliana (Fuck et al., 1993; Dardenne, 2000; Valeriano, 2017). Devido a essa imbricação, a idade desse grupo tem sido alvo de intensas discussões. O Grupo Vazante, em sua porção sul, isto é, entre as cidades de Lagamar e Coromandel (noroeste do estado de Minas Gerais), é composto principalmente pelas Formações Rocinha e Santo Antônio do Bonito. Essas duas formações representam um registro estratigráfico diferente e têm idades de sedimentação mais jovens do que o resto das formações do grupo (Pimentel et al., 2011; Rodrigues et al., 2012), fato que tem levado a questionamentos acerca da sua inclusão ou exclusão do Grupo Vazante.

Na última década, estudos têm sido desenvolvidos acerca do processo de enriquecimento em fosfato de origem sedimentar (Nelson et al., 2010; Pufahl, 2010; Pufahl e Groat, 2017). Uma das características desses depósitos de fosfato é a sua ocorrência episódica no registro sedimentar, ocorrida em zonas de ressurgência marinha (Kazakov, 1937; Cook, 1992; Föllmi, 1996; Boggs, 2006). O elemento fósforo $(\mathrm{P})$ é um dos macronutrientes primários presentes em fertilizantes. Esse macronutriente concentra-se em substâncias como o pentóxido de fósforo $\left(\mathrm{P}_{2} \mathrm{O}_{5}\right)$. A apatita, $\mathrm{Ca}_{5}\left(\mathrm{PO}_{4}\right)^{3}(\mathrm{~F}, \mathrm{OH}, \mathrm{Cl})$, é a forma mineralógica mais comum contendo fósforo. $\mathrm{Na}$ maioria dos depósitos sedimentares predominam as variedades carbonato-fluorapatita/francolita (McClellan e Kauwenbergh, 1990).

No Cráton do São Francisco, vários episódios fosfogenéticos são registrados em rochas do Pré-Cambriano, sendo Minas Gerais um dos principais locais de ocorrência de depósitos de fosfato do tipo sedimentar (Boujo et al., 1994; Dardenne et al., 1997; Uhlein et al., 2018). No Mesoproterozoico, este tipo de depósito ficou registrado em Parauninha (Minas Gerais), na Formação SopaBrumadinho, Supergrupo Espinhaço, conforme Mourão (1995). Entretanto, no Neoproterozoico esses depósitos são mais abundantes. Estes localizam-se em Irecê (Bahia), na Formação Salitre, Grupo Una, conforme Caird et al. (2017). Ocorrem em Campos Belos/Arraias (Goiás/Tocantins), na Formação Sete Lagoas, Grupo Bambuí, conforme Monteiro (2009) e Drummond et al. (2015). Existem, também entre as cidades de Lagamar e Coromandel (ambas em Minas Gerais), os depósitos de Lagamar, Rocinha e Coromandel, na Formação Rocinha/Santo Antônio do Bonito, Grupo Vazante, conforme Rocha-Araújo et al. (1992), Nogueira (1993), Sanches (2012) e Pufahl et al. (2016). E, por fim, os depósitos do início do Cambriano, em Cedro do Abaeté e Quartel Geral (Minas Gerais), na Formação Serra da Saudade, Grupo Bambuí, conforme Lima et al. (2007) e Moreira et al. (2020).

A fim de melhor entender o posicionamento estratigráfico das Formações Santo Antônio do Bonito e Rocinha e também dos depósitos de fosforitos sedimentares, discute-se o modelo sedimentar e estratigráfico para ambas as unidades do Grupo Vazante (ver localização na Figura 1). Ainda na porção sul desse grupo, são reinterpretados dados geocronológicos $\mathrm{U}-\mathrm{Pb}$ em zircões detríticos e apresentados novos dados Sm-Nd em diamictitos e pelitos. Esses dados no Grupo Vazante vêm corroborar algumas interpretações na área, mas principalmente calibrar a idade e a relação entre as duas formações basais, procurando um modelo estratigráfico regional. Esse novo conjunto de dados fornece idades máximas de deposição para ambas as formações do Grupo Vazante e sugere uma evolução vinculada à glaciação Criogeniana Jequitaí registrada no Cráton do São Francisco, Sudeste do Brasil. Além disso, na área ocorrem depósitos de fosforitos do Grupo Vazante que são descritos e comparados. São apresentados, de forma inédita, dados relativos a esses depósitos, sobretudo a primeira estratigrafia detalhada do depósito fosfático de Coromandel. A descrição e a interpretação dos processos sedimentológicos e estratigráficos relacionando diamictitos glaciais e gravitacionais com a fosfogênese são importantes contribuições para o entendimento das sucessões sedimentares do final do Neoproterozoico do Brasil.

\section{CONTEXTO GEOLÓGICO}

A Província Tocantins subdivide-se nas faixas neoproterozoicas Brasília, Araguaia e Paraguai, formadas pela 


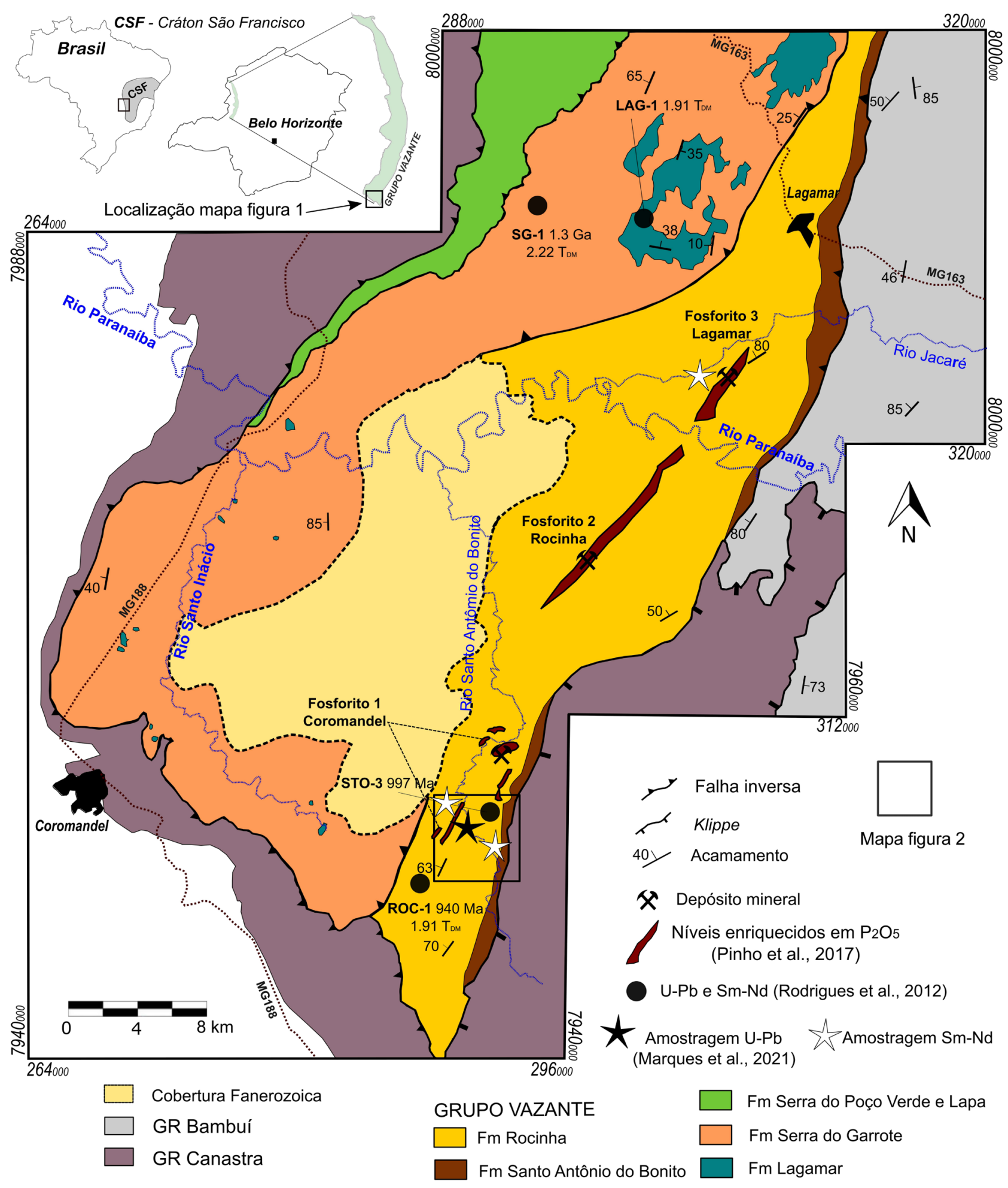

GR: grupo; Fm: formação.

Figura 1. Mapa Geológico na escala 1:100.000 entre as cidades de Coromandel e Lagamar, com localização da amostragem geocronológica U-Pb conforme Marques (2019) e Marques et al. (2021) e também a localização da amostragem para Sm-Nd, deste trabalho. Também são plotados os principais dados geocronológicos U-Pb e Sm-Nd de Rodrigues et al. (2012) e níveis fosforíticos (depósitos minerais) descritos por Dardenne (2000), delimitados por geofísica, de acordo com Pinho et al. (2017). 
colisão entre os paleocontinentes Amazonas, São Francisco e Paranapanema (Dardenne, 2000; Valeriano et al., 2004; Valeriano, 2017). O Cráton do São Francisco é composto por um embasamento arqueano-paleoproterozoico e por coberturas sedimentares pré-cambrianas do Supergrupo Espinhaço, do Grupo Paranoá e do Grupo Bambuí (Alkmim, 2004), além de coberturas fanerozoicas. A formação das margens passivas na porção ocidental do paleocontinente São Francisco foi iniciada com eventos de rifteamento Mesoproterozoico, formando diversas bacias extensionais que, no Toniano, passaram por processos de ampliação bacinal (Dardenne, 2000; Valeriano et al., 2004; Valeriano, 2017). Essas margens passivas são representadas por sucessões do Grupo Paranoá, Grupo Canastra, Grupo Vazante, Formação Jequitaí (Grupo Bambuí), Formação Cubatão (Grupo Ibiá) e parte do Grupo Araxá (Dardenne, 2000; Valeriano et al., 2004; Valeriano, 2017).

\section{Grupo Vazante}

$\mathrm{Na}$ região noroeste do estado de Minas Gerais, o Grupo Vazante abrange quase $10.000 \mathrm{~km}^{2}$, com $250 \mathrm{~km}$ de orientação geral N-S e largura média de $25-30 \mathrm{~km}$, aflorando próximo às cidades de Coromandel, Lagamar, Vazante, Paracatu e Unaí. Essas rochas metassedimentares compreendem uma espessa sucessão pelito-dolomítica que pode ser dividida em sete formações, da base ao topo: Santo Antônio do Bonito (diamictitos, arenitos e pelitos), Rocinha (ritmitos e pelitos), Lagamar (conglomerados do Membro Arrependido e calcários, dolomitos e pelitos do Membro Sumidouro), Serra do Garrote (pelitos com níveis arenosos), Serra do Poço Verde, Morro do Calcário e Lapa (essencialmente calcários, dolomitos e pelitos) (Dardenne et al., 1998; Dardenne, 2000, 2001; Fernandes, 2013; Oliveira, 2013; Marques et al., 2015; Marques et al., 2019; Sotero et al., 2019).

A Formação Santo Antônio do Bonito (Dardenne, 2001), também chamada de Formação Retiro (Dardenne, 2000), ocorre ao leste da cidade de Coromandel, nos Vales dos Rios Santo Antônio do Bonito e Santo Inácio, sendo caracterizada pela presença de horizontes de metadiamictitos com clastos de quartzito, calcário, dolomito, metassiltito e granito, imersos em matriz pelítica. Também ocorrem metarenitos e metapelitos localmente fosfatados (Fosforito 1 - Coromandel) (Souza, 1997; Dardenne, 2000). Na Formação Rocinha, em sua base, ocorre uma sequência metarítmica arenosa e pelítica, seguida por um espesso pacote de metapelitos e metassiltitos regularmente intercalados que passam, verticalmente, para metapelitos cinza escuro, carbonáticos e piritosos, com importantes ritmitos fosfáticos (Fosforito 2 - Rocinha). Na porção superior dessa formação, metaritmitos (quartzitos e metassiltitos) hospedam o depósito de fosfato de Lagamar (Fosforito 3 - Lagamar), constituído, essencialmente, por fosfarenitos (Nogueira, 1993; Dardenne, 2000).
Estudos iniciais sugeriram que os sedimentos do Grupo Vazante foram acumulados em uma configuração de margem passiva (Campos-Neto, 1984). Pimentel et al. (2011), utilizando dados geocronológicos U-Pb em zircão detrítico e dados isotópicos $\mathrm{Sm}-\mathrm{Nd}$, consideraram as Formações Santo Antônio do Bonito e Rocinha correlacionadas aos Grupos Paranoá e Canastra, definidos como sedimentos de margem passiva. Misi et al. (2014) propuseram que a parte inferior do Grupo Vazante, incluindo as Formações Santo Antônio do Bonito e Rocinha, é mais jovem (Neoproterozoico) do que a parte superior (final do Mesoproterozoico), com base nas idades de Re-Os em folhelhos orgânicos e dados U-Pb de zircão detrítico (Azmy et al., 2008; Rodrigues et al., 2012; Geboy et al., 2013). Trabalhos mais recentes apontam para uma idade neoproterozoica (Toniano) para todo o Grupo Vazante. Carvalho et al. (2019) identificaram idades com alguma contribuição toniana, isto é, idades-modelo $\mathrm{T}_{\mathrm{DM}} \mathrm{em}$ Sm-Nd entre 0,93 e 1,63 Ga (magmatismo intraplaca toniano proveniente do paleocontinente São Francisco) para as unidades de topo (Formação Lapa). Alvarenga et al. (2019) também interpretam essa idade toniana para toda a sucessão do Grupo Vazante em função da presença dos microfósseis Leiosphaeridia ternata e Bonnia dacruchares (Formação Lagamar), e por meio da quimioestratigrafia de $\delta^{13} \mathrm{C}, \delta^{18} \mathrm{O}$ $\mathrm{e}^{87} \mathrm{Sr} r{ }^{86} \mathrm{Sr}$ em carbonatos.

\section{Grupo Bambuí}

O Grupo Bambuí (Ediacarano-Cambriano), representa sucessão pelito-carbonática, abrangendo mais de 300.000 $\mathrm{km}^{2}$ do Cráton do São Francisco, no Centro-Leste do Brasil (Alkmim e Martins-Neto, 2001; Dardenne, 1978, 2000; Uhlein et al., 2017). Dardenne (1978) definiu seis formações, da base ao topo: Formação Jequitaí (constituída por diamictitos, arenitos e folhelhos); Formação Sete Lagoas (essencialmente carbonatos); Formação Serra de Santa Helena (siltitos, folhelhos e ritmitos); Formação Lagoa do Jacaré (carbonatos oolíticos e brechas intraformacionais); Formação Serra da Saudade (siltitos, folhelhos e arenitos); e Formação Três Marias (principalmente arenitos). Uhlein et al. (2017) propõem equivalentes laterais de algumas dessas formações para a parte ocidental da bacia. Essas formações consistem em conglomerados depositados em cunhas, denominadas formações Samburá e Lagoa Formosa, em níveis estratigráficos equivalentes às Formações Sete Lagoas e Serra da Saudade, respectivamente.

Sobre o paleocontinente São Francisco, durante o Neoproterozoico, uma glaciação de grandes proporções deixou como registro as rochas glaciais da Formação Jequitaí. Esta formação aflora em Minas Gerais e Goiás, materializando uma importante discordância entre o Mesoproterozoico (Supergrupo Espinhaço e Grupo Paranoá) e Neoproterozoico (Grupo Bambuí) (Karfunkel e Hoppe, 1988; Cukrov et al., 
2005; Uhlein et al., 2011; Martins-Ferreira et al., 2013). Essa unidade mostra predomínio de diamictitos, com espessura variável de $0-150 \mathrm{~m}$ na Serra do Cabral e na Serra da Água Fria, próximo da cidade Jequitaí. Para oeste, na região do domo de Cristalina (Goiás), a Formação Jequitaí apresenta espessura de cerca de $200 \mathrm{~m}$, com várias intercalações de diamictitos, arenitos e pelitos contendo dropstones, depositados em ambiente glaciomarinho (Cukrov et al., 2005; Uhlein et al., 2011). Esses trabalhos mostram que o ambiente de sedimentação da Formação Jequitaí varia de glaciocontinental a glaciomarinho, com geleira aterrada (pavimento estriado da Serra da Água Fria) e flutuante (diamictitos estratificados e pelitos com dropstones em Cristalina) (Karfunkel e Hoppe, 1988; Cukrov et al., 2005; Uhlein et al., 2011). A idade dessa glaciação ainda não é consensual. Segundo Babinski et al. (2007), a glaciação é Sturtiana, ocorrendo no início do Criogeniano, em torno de $720 \mathrm{Ma}$. Segundo Alvarenga et al. (2014), Caxito et al. (2012), Uhlein et al. (2016) e Uhlein et al. (2017), a glaciação é de idade Marinoana, do final do Criogeniano, ocorrendo em torno de $650 \mathrm{Ma}$. Ainda uma terceira opção foi sugerida, possível evento glacial Gaskiers, no final do Ediacarano ( 550 Ma; Kuchenbecker et al., 2016).

\section{Geologia e geocronologia do Grupo Vazante entre Coromandel e Lagamar}

A porção sul do Grupo Vazante, objeto de pesquisa deste trabalho, é constituída pelas unidades estratigráficas Santo Antônio do Bonito (metadiamictitos), Rocinha (metapelitos), Lagamar (metacalcários e dolomitos) e Serra do Garrote (metapelitos e quartzitos finos), que mostram imbricações tectônicas vergentes para o Cráton do São Francisco (Figura 1) (Marques, 2019; Marques et al., 2021). O Grupo Vazante é bordejado majoritariamente pelo Grupo Canastra, e uma pequena parte, ao leste, pelo Grupo Bambuí.

\section{Sedimentologia e estratigrafia das Formações Santo Antônio do Bonito e Rocinha}

Ao leste da cidade de Coromandel, no Vale do Rio Santo Antônio do Bonito, afloram os Grupos Canastra e Vazante (Figura 2). O Grupo Canastra tem espessura de aproximadamente $50 \mathrm{~m}$, representando apenas $10 \%$ da área do mapa. No Grupo Vazante, afloram as Formações Santo Antônio do Bonito e Rocinha (Figura 3) (Marques, 2019; Marques et al., 2021).

Na Formação Santo Antônio do Bonito ocorrem metadiamictitos, metarenitos, metassiltitos e metacalcários com espessura de $240 \mathrm{~m}$. Os metadiamictitos da Formação Santo Antônio do Bonito apresentam clastos de quartzito, calcário, dolomito, metassiltito, pelito e granitoide. Esses diamictitos constituem camadas de grande espessura (10 até $30 \mathrm{~m}$ ).
Quanto aos metarenitos, são médios a grossos, sendo classificados como subarcosianos.

A Formação Rocinha é a principal unidade, ocupando $\sim 70 \%$ da área, com espessura estimada de $1.050 \mathrm{~m}$, constituída, principalmente, por metapelito, metarenito e, localmente, metadiamictito. Os metarenitos da Formação Rocinha são predominantemente finos a médios e localmente mostram clastos dispersos. Esses metarenitos são, geralmente, quartzo-arenitos. Quanto aos diamictitos, ocorrem como corpos lenticulares e isolados, com pequena espessura (1 a $2 \mathrm{~m}$ ). Comumente gradam para arenitos e siltitos. Ocorrem, ainda, silexito e metassiltito silicificados adjacentes a falhas reversas.

Fácies sedimentares foram individualizadas de acordo com o litotipo, a geometria e as estruturas sedimentares, que permitem inferir os processos sedimentares. Considerando-se a ordem de abundância na área, foram identificadas as seguintes fácies: pelitos, arenitos, diamictitos e calcários. As interpretações dessas fácies, majoritariamente siliciclásticas, foram feitas de acordo com os processos sedimentares predominantes (Lowe, 1982; Walker, 1992; Arnott, 2010; Dalrymple, 2010).

Os pelitos são geralmente laminados com alternância rítmica (silte/argila ou silte/argila/areia fina), representando sedimentação distal por correntes de turbidez de baixa densidade. Localmente, siltitos maciços podem ocorrer, ou camadas sílticas gradadas, sugerindo também ação de correntes de turbidez distais. Os pelitos predominam ao oeste e representam, principalmente, a franja distal dos fluxos gravitacionais. Por sua vez, os arenitos são finos a grossos, às vezes conglomeráticos, ocorrem em camadas planas, são geralmente maciços, localmente gradados e mostram geometria plana ou lenticular. Esses arenitos correspondem a fluxos turbidíticos de alta e baixa densidade, depositados por fluxos gravitacionais do tipo correntes de turbidez ou ainda por fluxos de grãos ou liquefeitos, em contexto gravitacional (Shanmugam, 2000). Quando mostram geometria lenticular, devem representar canais submarinos com poder erosivo, em que as partículas são sustentadas, principalmente, pela pressão dispersiva entre os grãos (maciços), ou transporte grão-por-grão em suspensão pela turbulência do fluxo (e.g. Lowe, 1982; Shanmugam, 2000). Os diamictitos são conglomerados suportados pela matriz, contendo clastos de composição variada, com granulometria de seixo a matacão, variando de quartzo, quartzito, pelito, carbonato e granitoide. Representam fluxos gravitacionais subaquosos (muddy debris flow), interpretados como produto de avalanches submarinas. Por fim, o calcário é um calcarenito recristalizado e com alguns intraclastos, representando retrabalhamento de grãos carbonáticos em ambiente marinho raso.

Em função do arranjo estratigráfico das fácies sedimentares, em que diamictitos e arenitos grossos pertencem à Formação Santo Antônio do Bonito, e pelitos com arenitos 


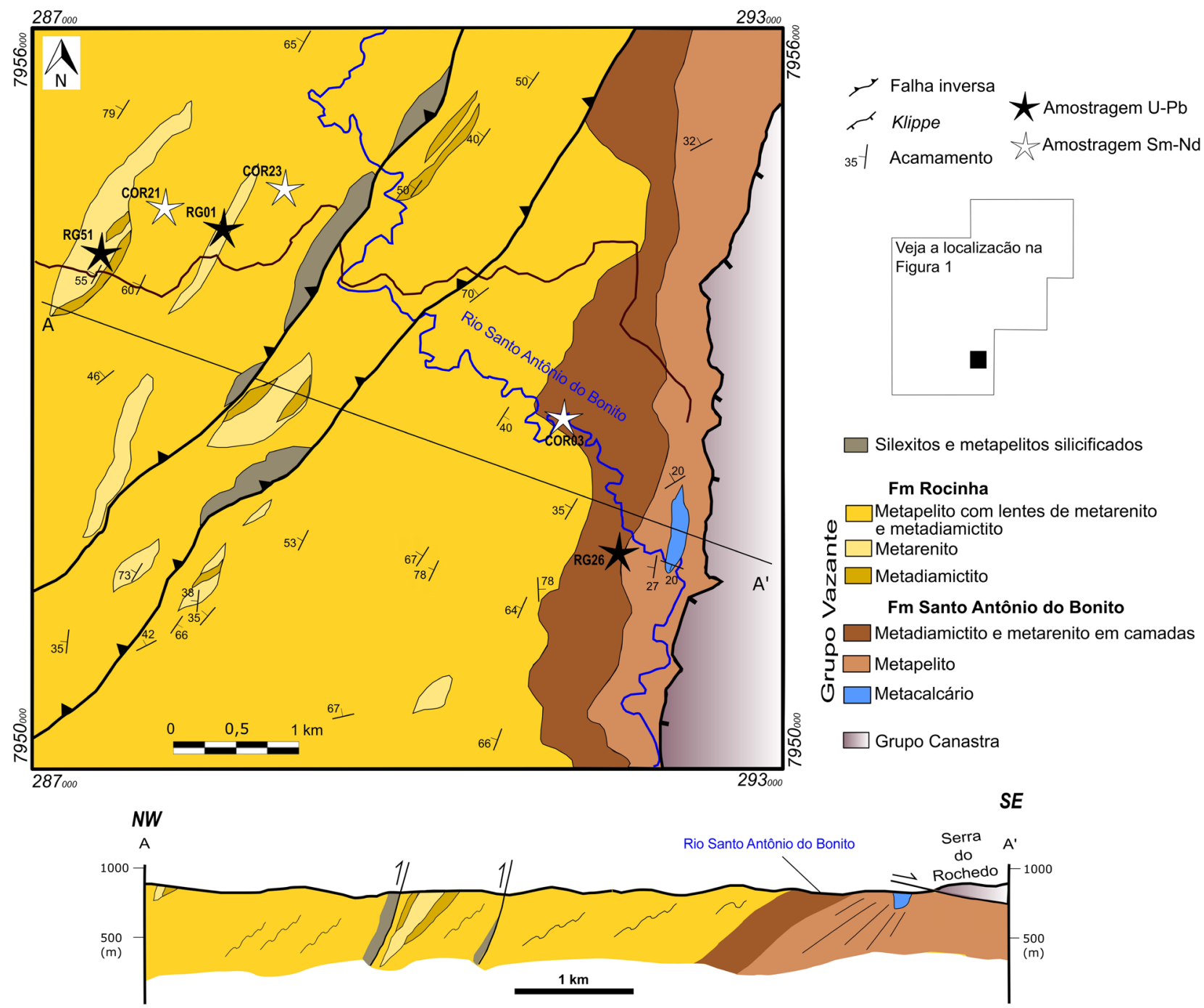

Fonte: adaptado de Marques (2019) e Marques et al. (2021).

Figura 2. Mapa geológico na escala 1:25.000 e seção geológica NW-SE no vale do Rio Santo Antônio do Bonito, leste de Coromandel (ver localização na Figura 1).

finos ocorrem na Formação Rocinha, relacionados a processos sedimentares como fluxos gravitacionais subaquosos, infere-se uma sedimentação de leque submarino (Figura 3A). Esse conjunto de leques submarinos bordejando a plataforma de um continente representa um sistema de cunhas clásticas subaquosas (slope-apron) (Figura 3B) (Lowe, 1982; Stow, 1985; Arnott, 2010).

\section{Geocronologia U-Pb em zircão detrítico}

A amostragem $\mathrm{U}-\mathrm{Pb}$ foi realizada ao longo da seção estratigráfica na região de Coromandel. A amostra RG26 ( $\mathrm{n}=57$; 59 grãos considerados para interpretação) pertence à Formação
Santo Antônio do Bonito, enquanto a RG01 (n=74) e RG51 $(\mathrm{n}=78)$ são da Formação Rocinha (Figuras 2 e 3 ). Os zircões detríticos foram concentrados a partir de três amostras de metarenitos com granulometria fina a média (Figura 4) (Marques, 2019; Marques et al., 2021).

Essas três amostras apresentam idade máxima de sedimentação dada a partir de 7 grãos jovens, cuja idade concórdia é de $934 \pm 8 \mathrm{Ma}$ (Figura 4A). Os seus histogramas exibem diversos picos de idade (padrão polimodal), cuja proporção de grãos neoproterozoicos representa $10 \%$ do conjunto de dados acumulados das 3 amostras $(n=209)$. Além disso, os zircões indicam as seguintes idades de proveniência: 10\% Esteniano; 10\% Ectasiano; 14\% Calimiano; 7\% 


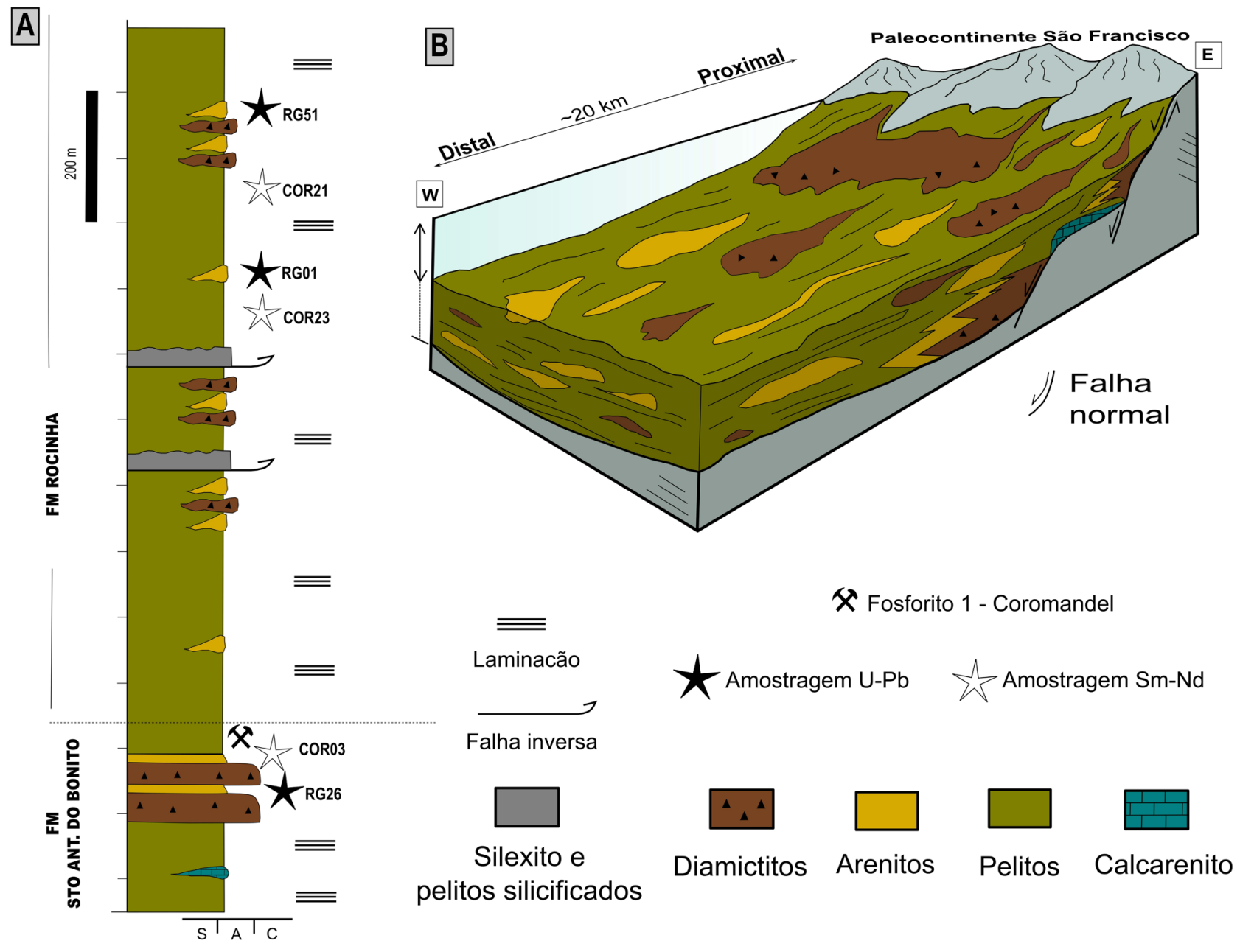

Figura 3. Sedimentologia/estratigrafia do Grupo Vazante a leste de Coromandel, de acordo com Marques (2019) e Marques et al. (2021). (A) Coluna estratigráfica; (B) Modelo sedimentar em ambiente marinho de slope-apron (cunhas clásticas subaquosas) na borda do Paleocontinente São Francisco.

Estateriano; $15 \%$ Orosiriano; 26\% Riaciano; 2\% Sideriano; e $6 \%$ Arqueano. As populações dominantes de zircões são representadas por grãos Riaciano $(\sim 2,1 \mathrm{Ga})$ e Esteniano/ Ectasiano $(\sim 1,2 \mathrm{Ga})$.

Comparando-se o histograma de idades U-Pb em zircões da Formação Santo Antônio do Bonito (Figura 4B) com a Formação Rocinha, é visível um aumento na proporção de grãos mesoproterozoicos e neoproterozoicos, e o pico de idade $\sim 2.1$ Ga deixa de ser proeminente (Figura $4 \mathrm{C}$ ). Observando-se o histograma de idades da Formação Jequitaí (Rodrigues, 2008; Figura 4D), verifica-se que este se assemelha com o das formações basais do Grupo Vazante, mas, sobretudo, com a Formação Santo Antônio do Bonito, onde o padrão de idade $\mathrm{U}-\mathrm{Pb}$ em zircões é predominantemente composto de uma população de idade paleoproterozoica $(2,0-2,2 \mathrm{Ga}) \mathrm{e}$, secundariamente, por picos arqueanos, mesoproterozoicos e neoproterozoicos consideravelmente menores.

\section{MATERIAIS E MÉTODOS}

As amostras coletadas para o método Sm-Nd visaram obter representação estratigráfica e ser preferencialmente de granulometria silte-argila, tendo maiores concentrações de Sm e Nd e melhor homogeneização das diferentes áreas fontes (McLennan, 1989). No caso da amostragem dos diamictitos, foram utilizadas apenas porções da matriz, desprezando quaisquer clastos com tamanho superior a grânulo. As amostras foram britadas manualmente e pulverizadas em moinho de disco de carbeto de tungstênio no SEPURA (Separação Mineral de Alta Pureza) do CPMTC (Centro de Pesquisa Manuel Teixeira da Costa) com um Moinho Modelo MPV-1. As 12 análises isotópicas Sm-Nd foram realizadas no espectrômetro de massa Triton, do Laboratório de Geologia Isotópica do Centro de Estudos em Petrologia e Geoquímica da Universidade Federal do 

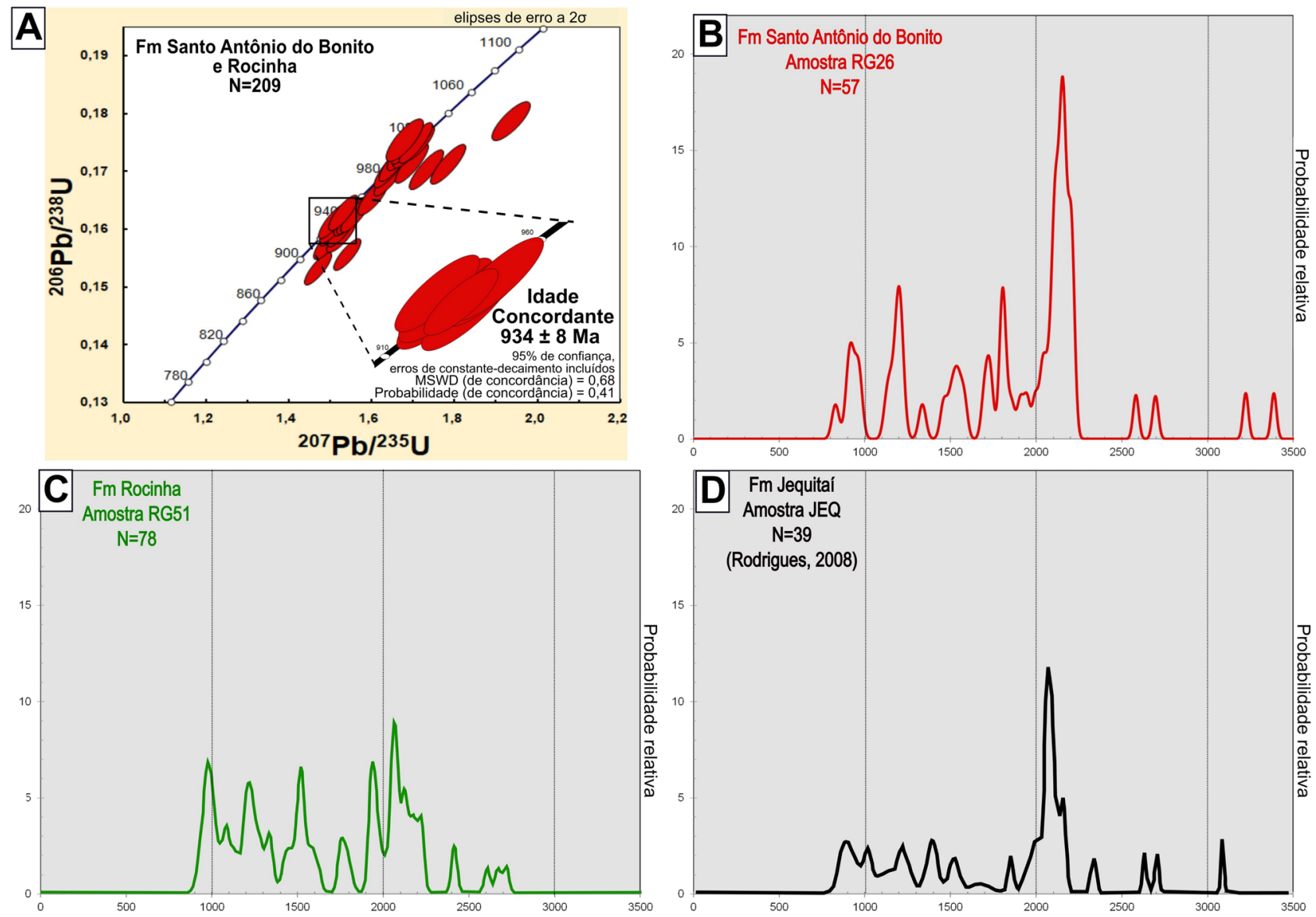

Figura 4. Dados U-Pb em zircão detrítico das Formações Santo Antônio do Bonito e Rocinha (Marques, 2019; Marques et al., 2021). (A) Idade concordante mais jovem das 3 amostras das unidades basais do Grupo Vazante ${ }^{206} \mathrm{~Pb} /{ }^{238} \mathrm{U}$, $\mathrm{n}=209$, Idade concórdia $934 \pm 8 \mathrm{Ma}$ ). (B, C e D) Histogramas de distribuição de idades ${ }^{207} \mathrm{~Pb} /{ }^{206} \mathrm{~Pb}$ : (B) Formação Santo Antônio do Bonito; (C) Formação Rocinha; (D) Formação Jequitaí (Rodrigues, 2008).

Rio Grande do Sul. Para cada amostra, foram realizadas, em média, 100 razões isotópicas, com $1,0 \mathrm{~V}$ de intensidade iônica para ${ }^{146} \mathrm{Nd}$ e multicoleção com 146 no coletor axial, análises normalizadas para ${ }^{146} \mathrm{Nd} /{ }^{144} \mathrm{Nd}=0,7219$ e ajustadas para bias com base no Nd SPEX, assumindo ${ }^{143} \mathrm{Nd} /{ }^{144} \mathrm{Nd}$ $=0,511110$ e calibrado contra $\mathrm{Nd}$ La Jolla, assumindo um valor de ${ }^{143} \mathrm{Nd} /{ }^{144} \mathrm{Nd}$ de 0,511856 . $\varepsilon \mathrm{Nd} \mathrm{e}{ }^{143} \mathrm{Nd} /{ }^{144} \mathrm{Nd}(\mathrm{t})$ : calculado para idade de $600 \mathrm{Ma}$. Branco $\mathrm{Nd}<160 \mathrm{pg}$. $\mathrm{T}_{\mathrm{DM}}=$ idade-modelo Sm-Nd manto depletado. SE $(\%)=$ standard error percentual.

Vinte e seis lâminas delgadas do Grupo Vazante na região de Lagamar e Coromandel foram observadas em um microscópio petrográfico de luz transmitida e refletida ZEISS modelo Axioskop 40 do LABTEC Rochas do CPMTC-IGC/ UFMG. Oito amostras de ritmitos fosfáticos foram estudadas e descritas. Dessas lâminas, três são do depósito de Lagamar (Fosforito 3), três do depósito Rocinha (Fosforito 2) e duas do depósito de Coromandel (Ponte Caída, Fosforito 1), visando à comparação petrográfica.

São também apresentados neste trabalho dados inéditos sobre a estratigrafia do depósito de fosfato de Coromandel (também chamado de Ponte Caída), a partir de furos de sondagem da empresa Jacutinga Desenvolvimento Mineral (JDM).

\section{DADOS ISOTÓPICOS SM-ND}

Foram coletadas seis amostras para determinação isotópica Sm-Nd no Grupo Vazante, quatro pelitos da Formação Rocinha e duas amostras de matriz de diamictitos da Formação Santo Antônio do Bonito (Tabela 1). As amostras LA304 e LA306 são pelitos coletados próximos da cidade de Lagamar (Figura 1), e os pelitos COR21 e COR23 
Tabela 1. Dados isotópicos e quantidades de Sm e Nd do Grupo Vazante (Formações Santo Antônio do Bonito e Rocinha) e do Grupo Bambuí (Formações Serra de Santa Helena e Jequitaí). Idades-modelo $T_{D M}(G a)$ calculadas de acordo com DePaolo (1988)

\begin{tabular}{|c|c|c|c|c|c|c|c|c|c|c|c|c|}
\hline nostra & Litotipo & $\begin{array}{c}\mathrm{Sm} \\
(\mathrm{ppm})\end{array}$ & $\begin{array}{c}\mathrm{Nd} \\
(\mathrm{ppm})\end{array}$ & ${ }^{147} \mathrm{Sm} /{ }^{144} \mathrm{Nd}$ & $E(\%)$ & $\begin{array}{l}{ }^{143} \mathrm{Nd} / \\
{ }^{144} \mathrm{Nd}\end{array}$ & $F(0)$ & $\begin{array}{c}\varepsilon \mathrm{Nd} \\
(0)\end{array}$ & $\begin{array}{c}\varepsilon \mathbf{N d} \\
\text { (t) }\end{array}$ & $\mathrm{T}_{\mathrm{DM}}$ & $\begin{array}{l}{ }^{143} \mathrm{Nd} / \\
{ }^{144} \mathrm{Nd}\end{array}$ & $t_{11}$ \\
\hline $304^{*}$ & elito & 5,8 & 35,5 & 46 & 6 & 0,511621 & 023 & $-19,8$ & $-12,4$ & 1.9 & 0,511230 & 600 \\
\hline & & 13,0 & 87,8 & & &, 511804 & & & & 5 & 0,51 & 600 \\
\hline & & & 59 , & & & 511449 & & & & 1.9 & & 600 \\
\hline & & & - & & & 59 & & & & & & 600 \\
\hline & & & & & & 0 & & & & 8 & & 600 \\
\hline & & & & & & 99 & & & $-10,7$ & 2.1 & & 600 \\
\hline & & & 33 & & & 0,51 & & -1 & 0 & .4 & 58 & 600 \\
\hline & & & 36 & & & 26 & & & 4 & .7 & 34 & 00 \\
\hline & & & & & & & & & & 1.5 & & 00 \\
\hline & & & & & & & & & & 1.1 & & 500 \\
\hline & & & 19 & & & & & $-18,7$ & $-11,5$ & 1,9 & 277 & 600 \\
\hline$E Q 2^{\circ}$ & Diamictito & 2,5 & 13,5 & 0,109946 & 0,091824 & 0,511715 & 0,0016 & $-18,0$ & $-11,4$ & 1.9 & 0,511283 & 600 \\
\hline
\end{tabular}

\$Amostras do Grupo Vazante: *Fm Rocinha, ×Fm Santo Antônio do Bonito; Amostras do Grupo Bambuí: "Fm Serra de Santa Helena, ${ }^{\circ} F m$ Jequitaí.

afloram na margem oeste do Rio Santo Antônio do Bonito (Figura 2). Os diamictitos COR03 e RG26 afloram no Vale do Rio Santo Antônio (Figura 2, ver também coordenadas geográficas no Anexo 1).

Para a comparação isotópica, foram coletadas seis amostras do Grupo Bambuí, sendo que quatro amostras foram de pelitos da Formação Serra de Santa Helena (próximo à cidade de Paraopeba, amostras SH1 topo e base e SH2 topo e base). Foram ainda coletadas duas amostras de matriz de diamictitos da Formação Jequitaí, nos arredores da cidade homônima (amostras JEQ 1 e JEQ 2, conforme Figura 5 e Tabela 1, coordenadas geográficas no Anexo 1).

Para a Formação Rocinha, as rochas pelíticas analisadas têm concentrações de Sm e Nd variando de 5,8-13 ppm a 35,5-87,8 ppm, respectivamente. Mostram idades-modelo $\left(\mathrm{T}_{\mathrm{DM}}\right)$ variando de 1,5-1,9 Ga, enquanto os valores de $\varepsilon \mathrm{Nd}_{(t \in 600)}$ são negativos $(-8,1$ a -14,8). Para a Formação Santo Antônio do Bonito, a concentração de Sm varia de 3,8-7,2 ppm e o Nd, de $21,6-35,7 \mathrm{ppm}$. As amostras investigadas correspondem à matriz de diamictitos e têm idades-modelo de 1,8 e $2,1 \mathrm{Ga}$. Os valores de $\varepsilon \mathrm{Nd}_{(\mathrm{t}-600)}$ também são negativos: $-10,3$ a $-10,7$.

Na Formação Serra de Santa Helena, as rochas pelíticas analisadas apresentam concentrações de Sm entre 4,4-8,7 ppm e Nd de 26,3-55,7 ppm. Têm idades-modelo variando de $1,1-1,7 \mathrm{Ga}$, e os valores de $\varepsilon \mathrm{Nd}_{(t-600)}$ também são negativos, com variações de -1,5--7,4. Para a Formação Jequitaí, as amostras investigadas correspondem à matriz de diamictitos, cujas concentrações de Sm variam de 2,5-3,2 ppm e $\mathrm{Nd}$ de 13,5-19,0 ppm. Essas rochas têm idade-modelo de $1,9 \mathrm{Ga}$, com valor de $\varepsilon \mathrm{Nd}_{(\mathrm{t}=600)}$ de $-11,4--11,5$.

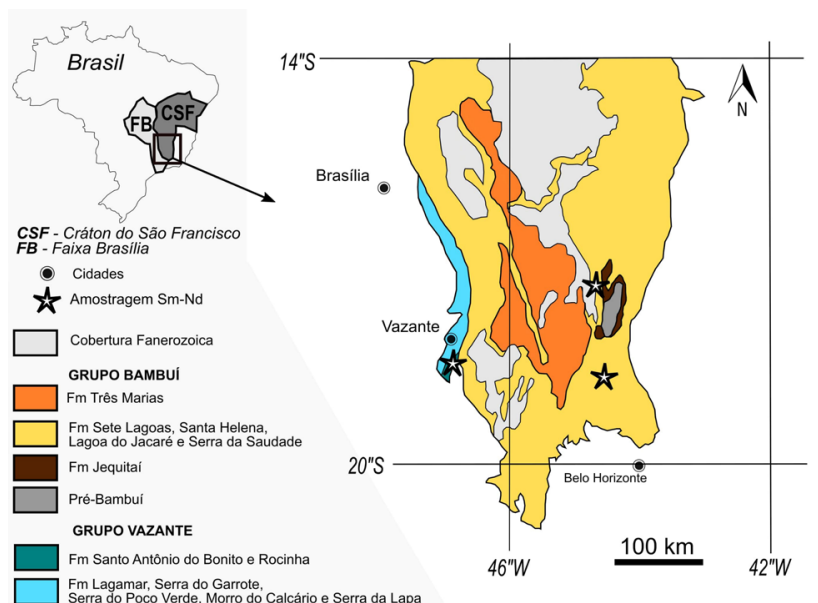

Fm: formação.

Fonte: modificada de Misi (2001).

Figura 5. Localização das amostras analisadas pelo método isotópico Sm-Nd nos Grupos Vazante e Bambuí, no domínio sul do Cráton do São Francisco. Amostras da Formação Jequitaí nos arredores da cidade homônima e da Formação Serra de Santa Helena nos arredores da cidade de Paraopeba.

A evolução do $\varepsilon N d$ no tempo e nas idades-modelo do Grupo Vazante e do Grupo Bambuí pode ser observada na Figura 6. Esta figura mostra diferentes espectros de idade, com as rochas do Grupo Vazante em geral com $T_{D M}$ mais antigos, entre 1,5-2,1 Ga, enquanto para o Grupo Bambuí aparecem idades $\mathrm{T}_{\mathrm{DM}}$ um pouco mais novas, entre $1,1-1,9 \mathrm{Ga}$. 


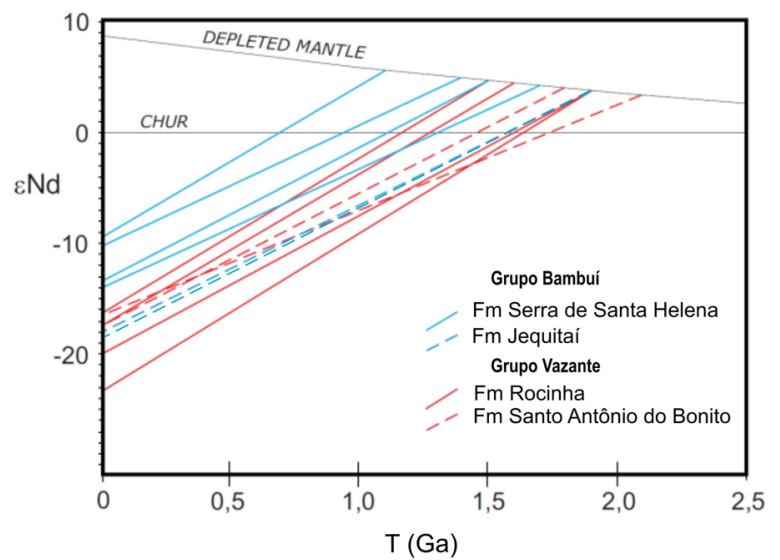

Fm: Formação.

Figura 6. Diagrama $\mathrm{Nd} \times$ tempo $(\mathrm{Ga})$ para as rochas do Grupo Vazante e do Grupo Bambuí, em referência as curvas do manto depletado (depleted mantle) e do condrito (CHUR) de acordo com McLennan (1989).

\section{FOSFORITOS SEDIMENTARES DO GRUPO VAZANTE}

As rochas enriquecidas em fosfato (fosforitos) do Grupo Vazante localizam-se na porção sul desta unidade, entre as cidades de Coromandel e Lagamar (ver Figura 1), e foram designadas de fosforitos 1, 2 e 3 (Dardenne et al., 1986; Dardenne et al., 1997; Dardenne, 2000). Destacam-se a Mina da Galvani (Fosforito 3; Figura 7A), situada ao sul de Lagamar; a Mina da Rocinha (Fosforito 2; Figura 8A), entre a cidade de Lagamar e Coromandel; e o depósito de Coromandel (ou Ponte Caída), situado mais ao sul, no Vale do Rio Santo Antônio do Bonito, ainda não explotado (Fosforito 1; Figura 9). Em geral, são ritmitos fosfáticos que ocorrem intercalados com siltitos e ardósias ou siltitos carbonáticos da Formação Rocinha. O depósito de Coromandel é ainda pouco conhecido. O resumo dos dados referentes aos três depósitos fosfáticos do Grupo Vazante é apresentado na Tabela 2.

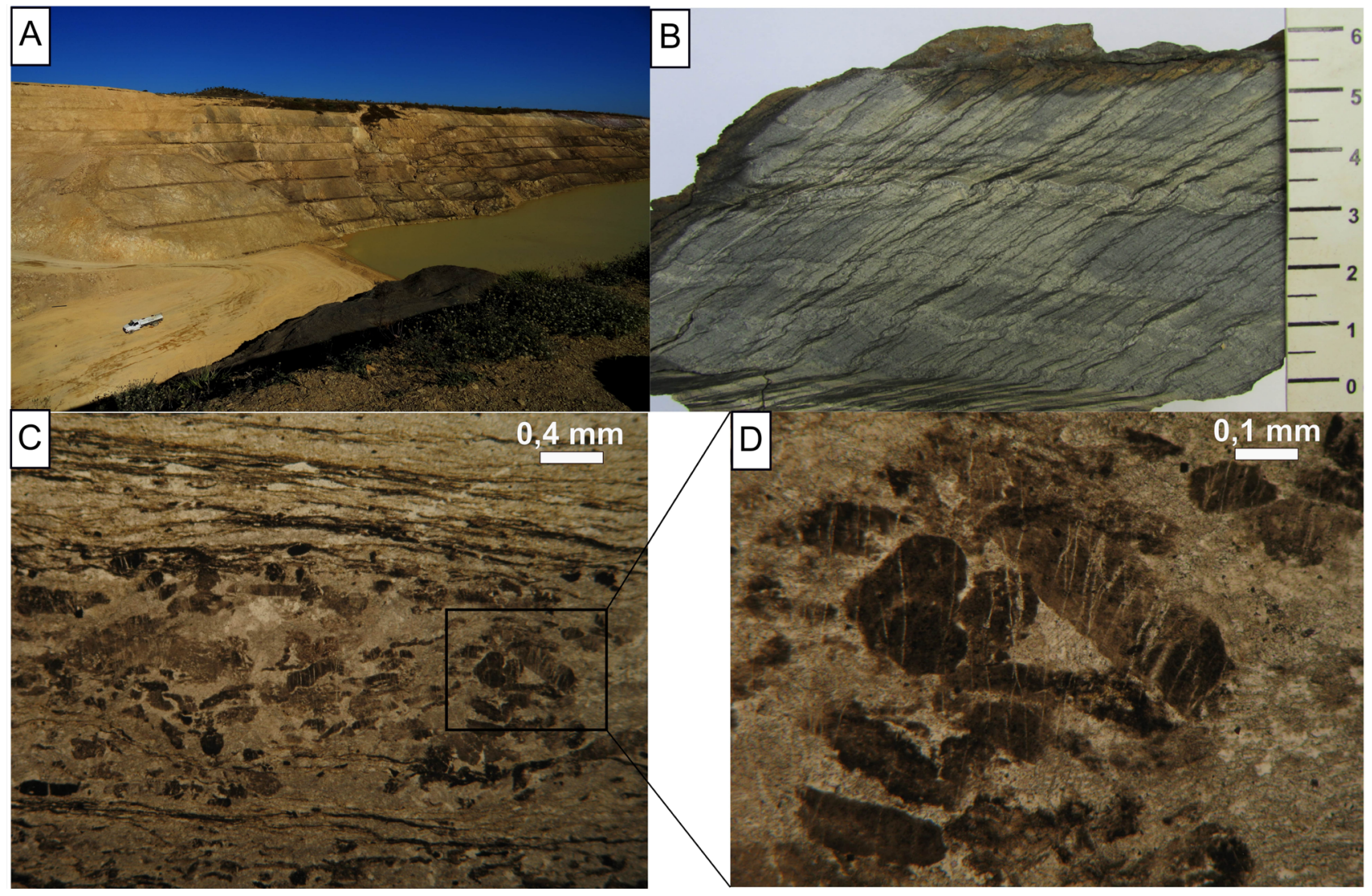

Figura 7. Depósito de fosfato de Lagamar, operado pela empresa Galvani Fertilizantes (Lavra C). (A) Visão geral da mina, com bancadas a céu aberto. (B) Amostra de ritmito fosfático carbonático mostrando clivagem oblíqua ao acamamento. (C) Fotomicrografia de ritmito fosfático, com alternância de fosfolutitos e fosfoarenitos, mostrando intraclastos fosfáticos (fosforito retrabalhado, granular); 10×, nícois paralelos. (D) Fotomicrografia de detalhe nos intraclastos fosfáticos, com fraturas e imersos em matriz de calcita e apatita microcristalina; 40x, nícois paralelos. 


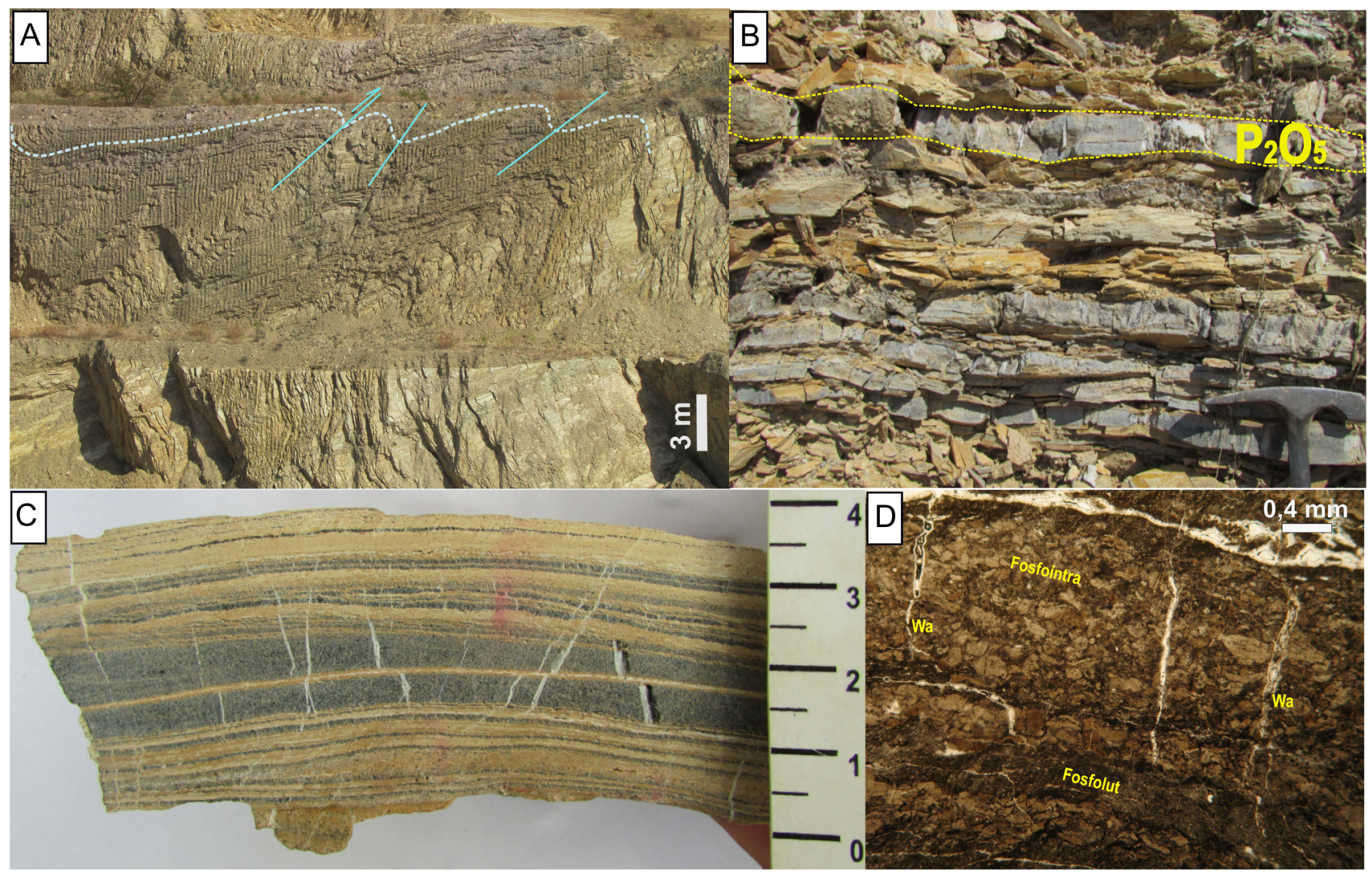

Figura 8. Depósito fosfático de Rocinha. (A) Ritmitos mostrando dobras assimétricas nas bancadas de lavra. (B) Ritmito fosfático com níveis cinza centimétricos enriquecidos em $\mathrm{P}_{2} \mathrm{O}_{5}$. (C) Amostra de ritmito fosfático com níveis escuros enriquecidos com fosfointraclastos e fraturas preenchidas por wavellita. (D) Fotomicrografia de ritmito fosfático com níveis intraclásticos (Fosfolntra) tamanho areia, matriz micrítica nos níveis fosfolutitico, e minerais de wavellita (Wa) nas fraturas; 10× nícois paralelos.

O depósito de Lagamar tem teor médio de 10-15\%, localmente atingindo 38\% (Nogueira, 1993), com volume de 5 Mt (CPRM, 1976). A rocha hospedeira é constituída por ritmitos predominantemente arenosos (fosfoarenitos), com 200-300 m de espessura (Nogueira, 1993). A mina encontra-se instalada em local de maior concentração das camadas de fosfoarenitos, cujos níveis arenosos são de espessuras centimétricas (Figura 7A). Abaixo do depósito, as rochas encaixantes são ardósias calcíferas e o topo é constituído por siltitos amarelados. A rocha fosfática é um ritmito areno-carbonático-argiloso com lâminas e camadas milimétricas a centimétricas (Figura 7B). Em lâmina delgada, ocorre alternância de fosfolutito e fosfoarenito carbonático com intraclastos fosfáticos (Figura 7C). Esses intraclastos variam de subarredondados a subangulosos, bastante fraturados, com fraturas preenchidas por wavellita, e encontram-se imersos em uma matriz fosfática de apatita microcristalina (Figura 7D).
O depósito de Rocinha apresenta teor médio de 10-15\%, localmente atingindo 30\% (Rocha-Araújo et al., 1992), com volume de $415 \mathrm{Mt}$. A rocha hospedeira é um ritmito, com lâminas alternadas de fosfoarenitos e fosfolutitos. Estratigraficamente, abaixo do depósito ocorrem pelitos carbonáticos (Rocha-Araújo et al., 1992; Nogueira, 1993). Os metaritmitos são predominantemente argilosos (fosfolutitos), com 25-30 m de espessura, com níveis escuros silto-arenosos centimétricos a decimétricos, enriquecidos em apatita em grãos, pellets e intraclastos (Figuras 8B). A rocha hospedeira deste depósito é um ritmito areno-argiloso com fraturas preenchidas por wavellita (Figura 8C). Ao microscópio, observa-se intercalação de fosfoarenitos ricos em intraclastos angulosos (Figura 8D). Esses intraclastos são de granulometria areia fina/média com matriz micrítica fosfática, atravessados por fraturas preenchidas por wavellita, formando, por vezes, agregados fibroradiais. 


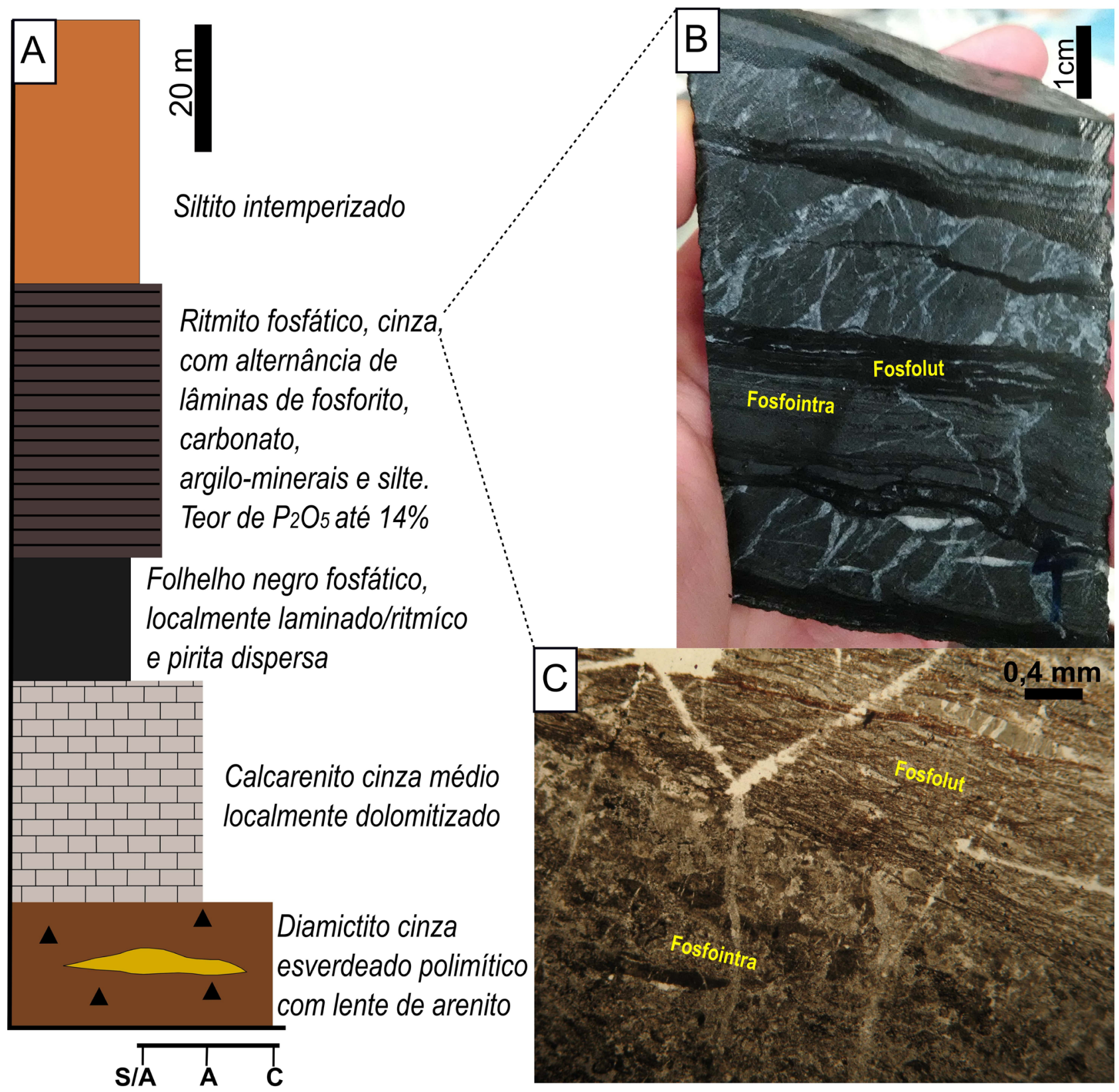

Figura 9. Depósito fosfático de Coromandel. (A) Estratigrafia do depósito de Coromandel a partir de furos de sondagem da empresa Jacutinga Desenvolvimento Mineral (JDM). (B) Amostra de ritmito fosfático em furo de sondagem. (C) Fotomicrografia de ritmito fosfático com alternância de níveis fosfointraclásticos (Fosfointra) e fosfolutíticos (Fosfolut), $10 \times$ nícois paralelos.

Mais ao sul, próximo da cidade de Coromandel, existe o depósito Ponte Caída (CPRM, 1979) ou depósito Coromandel (Dardenne, 2000), que se situa no Vale do Ribeirão Santo Antônio do Bonito e aparece localizado na Figura 2. É um depósito de $\mathrm{P}_{2} \mathrm{O}_{5}$ ainda não explotado. De acordo com o projeto pioneiro de pesquisa mineral da CPRM (1979 - Furo 002), esse depósito indica teores máximos de $11,1 \%$ aos $16 \mathrm{~m}$ de profundidade, podendo chegar até $20,6 \%$ em níveis centimétricos em outros furos de sondagem. A reserva foi avaliada em 298.9 Mt e teor médio 6,74\% (CPRM, 1979). Recentemente, Teles (2019) apresenta valores de 34\% de $\mathrm{P}_{2} \mathrm{O}_{5}$ em amostras de siltitos fosfatados.

A partir de testemunhos de furos de sondagem realizados pela empresa de prospecção JDM, o depósito de Coromandel mostra, da base para o topo, a seguinte estratigrafia (Figura 9A): diamictito cinza esverdeado polimítico, 
Tabela 2. Resumo comparativo dos depósitos de fosfato sedimentar no Grupo Vazante.

\begin{tabular}{|c|c|c|c|c|}
\hline Depósito & Volume e teor de $\mathrm{P}_{2} \mathrm{O}_{5}$ & Rocha hospedeira & $\begin{array}{l}\text { Paleoambiente e } \\
\text { mecanismo de } \\
\text { fosfogênese }\end{array}$ & $\begin{array}{l}\text { Mineral } \\
\text { fosfático }\end{array}$ \\
\hline $\begin{array}{l}\text { Lagamar } \\
\text { (Fosforito 3) }\end{array}$ & $\begin{array}{c}\text { Reserva } 5 \text { Mt (CPRM, } \\
\text { 1976); 10-15\%, localmente } \\
\text { atingindo 38\% (Nogueira, } \\
\text { 1993). }\end{array}$ & $\begin{array}{l}\text { Ritmitos fosfáticos } \\
\text { (fosfoarenitos/fosfolutitos), com } \\
\text { predomínio de fosfoarenitos em } \\
\text { níveis centimétricos. }\end{array}$ & $\begin{array}{l}\text { Borda de plataforma } \\
\text { continental com } \\
\text { ressurgência marinha. }\end{array}$ & $\begin{array}{l}\text { Carbonato- } \\
\text { fluorapatita } \\
\text { Wavellita }\end{array}$ \\
\hline $\begin{array}{l}\text { Rocinha } \\
\text { (Fosforito 2) }\end{array}$ & $\begin{array}{l}\text { Reserva } 415 \text { Mt; 10-15\%, } \\
\text { localmente atingindo 30\% } \\
\text { (Rocha-Araújo et al., 1992); }\end{array}$ & $\begin{array}{c}\text { Ritmitos fosfáticos } \\
\text { (fosfoarenitos/fosfolutitos), } \\
\text { com predomínio de fosfolutitos } \\
\text { e níveis fosfoareníticos } \\
\text { centimétricos a decamétricos. }\end{array}$ & $\begin{array}{l}\text { Borda de plataforma } \\
\text { continental com } \\
\text { ressurgência marinha. }\end{array}$ & $\begin{array}{l}\text { Carbonato- } \\
\text { fluorapatita } \\
\text { Wavellita }\end{array}$ \\
\hline $\begin{array}{l}\text { Coromandel } \\
\text { (Fosforito 1) }\end{array}$ & $\begin{array}{c}\text { Reserva 298.9 Mt e teor } \\
\text { médio 6,74\% (CPRM, } \\
\text { 1979); 34\% em siltitos } \\
\text { fosfatados (Teles, 2019). }\end{array}$ & $\begin{array}{l}\text { Ritmitos fosfáticos } \\
\text { (fosfoarenitos/fosfolutitos), com } \\
\text { predomínio de fosfoarenitos em } \\
\text { níveis centimétricos. }\end{array}$ & $\begin{array}{l}\text { Borda de plataforma } \\
\text { continental com } \\
\text { ressurgência marinha } \\
\text { e/ou com precipitação } \\
\text { direta do fosfato, } \\
\text { proveniente do } \\
\text { paleocontinente. }\end{array}$ & $\begin{array}{l}\text { Carbonato- } \\
\text { fluorapatita } \\
\text { Wavellita }\end{array}$ \\
\hline
\end{tabular}

com lente de arenito, calcarenito de cor cinza médio, folhelho negro, localmente laminado, ritmito fosfático e pelitos alterados (Figura 9A). O enriquecimento em fosfato até 14\% ocorre nos níveis de ritmito fosfático, com enriquecimento maior nos níveis arenosos dessa fácies. Esse ritmito fosfático é areno-argilo-carbonático (Figura 9B). As lâminas cinzas são carbonáticas ricas em microveios. $\mathrm{O}$ acamamento plano-paralelo é bem evidente e constitui a feição primária fundamental em que se observa alternância de arenito fino e pelito. Os fosforitos e as encaixantes encontram-se dobrados, com desenvolvimento de foliação incipiente nas rochas mais finas e clivagens espaçadas nas rochas mais competentes, além da presença de alguns falhamentos. Em lâmina delgada (Figura 9C), observam-se intercalação de fosfoarenitos (ricos em intraclastos angulosos) e níveis fosfolutíticos. Esses intraclastos estão fraturados, imersos em uma matriz fosfática de apatita microcristalina, com alguns grãos de quartzo.

\section{DISCUSSÃO}

\section{Correlações regionais}

No paleocontinente São Francisco ocorreu uma grande glaciação no Neoproterozoico, com formação de pavimentos estriados e sedimentação glacial em contexto continental e marinho, depositando diamictitos, arenitos e pelitos da Formação Jequitaí (Karfunkel e Hoppe, 1988; Cukrov et al., 2005; Uhlein et al., 2011; Martins-Ferreira et al., 2013). Esses depósitos glaciais foram retrabalhados em direção às faixas dobradas (bacias marginais) que envolveram o paleocontinente São Francisco, tanto para oeste como para leste. Para oeste, em direção à Faixa Brasília, houve espessamento da Formação Jequitaí, que ocorre bem preservada, com fácies glaciomarinhas no domo de Cristalina (Cukrov et al., 2005). Assim, acreditamos que a Formação Santo Antônio do Bonito pode ser correlacionada com a Formação Jequitaí devido à grande semelhança entre as fácies sedimentares e os dados geocronológicos U-Pb em zircão detrítico. Possivelmente, houve retrabalhamento por sistema de falhas normais e sedimentação gravitacional subaquosa importante aproximadamente contemporânea à glaciação Jequitaí.

No entanto, comparando-se as fácies sedimentares e os dados geocronológicos das Formações Santo Antônio do Bonito e Rocinha, a última apresenta predomínio de fácies sedimentares de granulometria fina (ritmitos e siltitos) e aumento da quantidade de grãos mesoproterozoicos e neoproterozoicos para o topo. $\mathrm{O}$ fato de estar posicionada estratigraficamente acima da Formação Santo Antônio do Bonito e compondo um padrão tipicamente retrogradacional sugere que a Formação Rocinha seja um produto sedimentar da subida do nível do mar em contexto pós-glacial. Ocorreu, então, mudança nos processos sedimentares e nas áreas fontes (proveniência), passando de um registro mais proximal na Formação Santo Antônio do Bonito para um mais distal na Formação Rocinha.

Quanto aos dados isotópicos de Sm-Nd, os diamictitos, tanto do Grupo Vazante (Formação Santo Antônio do Bonito) como do Grupo Bambuí (Formação Jequitaí) mostram fontes com idade média de extração mantélica Paleoproterozoica $(1,8-2,1 \mathrm{Ga})$ e $\varepsilon \mathrm{Nd}_{(\mathrm{t}=600)}$ em torno de -11, possivelmente representando erosão do paleocontinente São Francisco. Pode-se comprovar que os dados de 
Sm-Nd reforçam a correlação proposta pelos dados geocronológicos. As rochas pelíticas apresentam idades $T_{D M}$ progressivamente mais jovens, sendo 1,6 - 1,9 Ga para a Formação Rocinha (Grupo Vazante) e 1,1 - 1,7 Ga para a Formação Serra de Santa Helena (Grupo Bambuí). Esta última unidade, a Formação Serra de Santa Helena, apresenta valores que refletem proveniência mista do paleocontinente São Francisco e do Arco Magmático de Goiás (ou do antigo arco magmático da Faixa Araçuaí), como foi sugerido por Pimentel et al. (2011) e corroborado neste trabalho ( $\mathrm{T}_{\mathrm{DM}}$ mais jovens e $\varepsilon \mathrm{Nd}_{(\mathrm{t}=600)}$ menos negativos).

Assim, considerando-se a presença de diamictitos em ambas as formações, o modelo deposicional a partir de fluxos gravitacionais submarinos e as idades $\mathrm{U}-\mathrm{Pb}$ em zircão detrítico e Sm-Nd semelhantes, reforça-se a correlação entre a Formação Santo Antônio do Bonito (Grupo Vazante) e a Formação Jequitaí (Grupo Bambuí), conforme já sugerido por Souza (1997), Misi et al. (2011), Teles (2019) e Marques et al. (2021).

A Figura 10 ilustra a evolução deposicional das Formações Santo Antônio do Bonito e Rocinha e a correlação sugerida com a Formação Jequitaí. Teles (2019) identificou clastos com estrias consideradas glaciais nos diamictitos da Formação Santo Antônio do Bonito, confirmando, também por dados de campo, o retrabalhamento das sequências glaciomarinhas da Formação Jequitaí (Figura 10 - I). Em fase tardia, ou logo após a glaciação, houve condições (tectônica extensional) de formar depósitos de retrabalhamento de fácies glaciais em contexto de slope-apron submarino. Associados a esses depósitos gravitacionais ocorria sedimentação de calcários e enriquecimento de fosfato em pelitos, em uma fase inicial da transgressão que trazia fósforo de águas mais profundas para águas mais rasas. Outra provável fonte de fósforo seria a água de degelo continental, especialmente para o depósito de Coromandel, imediatamente após a glaciação (Okubo et al., 2018; Teles, 2019). Nesse tempo teria se formado o depósito de Coromandel, situado estratigraficamente próximo dos diamictitos (Figura $10-$ II). Com a progressiva elevação do nível dos mares após a glaciação, os fluxos gravitacionais são enfraquecidos, passando a predominar a sedimentação areno-pelítica, possibilitando o desenvolvimento de processos de ressurgência durante a fase de máxima expansão da bacia (Stow, 1985; Arnott, 2010). Esse contexto permitiu, assim, a instalação dos depósitos Lagamar e Rocinha, associados a uma provável superfície de inundação máxima (Figura 10 - III).

\section{Fosfogênese neoproterozoica}

A sedimentação fosfática que compõe os depósitos das formações basais do Grupo Vazante ocorreu em ambiente marinho pericontinental ou de margem passiva, rico em matéria orgânica. $\mathrm{O}$ enriquecimento sedimentar em fosfato possibilitou a formação de um minério sedimentar estratiforme, com fluorapatita disseminada e granular, principalmente na forma de fosfoarenitos, enriquecidos em pellets e intraclastos.

O processo de fosfogênese dos depósitos do Grupo Vazante pode ser sintetizado em cinco etapas. Primeiro, ocorre o processo de ressurgência na bacia marinha plataformal. Nesse processo, as correntes marinhas do fundo (com fosfato dissolvido, ambiente redutor e $\mathrm{pH}$ ácido) chegam à costa, onde predominam águas oxidantes, com $\mathrm{pH}$ levemente alcalino. Ocorre, então, a segunda etapa, com a sedimentação de uma lama fosfática e calcítica (com o possível auxílio de bactérias) formando francolita (mineral fosfático primário). Na terceira etapa, há retrabalhamento sedimentar produzido por correntes, talvez induzido pelos fluxos gravitacionais, formando intraclastos fosfáticos. Depois, na quarta etapa, ocorrem processos diagenéticos (principalmente soterramento) e/ou meteóricos, formando fluorapatita criptocristalina. Por fim, o intemperismo proporciona a alteração supergênica, materializada na ocorrência do mineral de alteração preenchendo fraturas, rico em alumínio, do tipo wavellita (Föllmi, 1996; Dardenne et al., 1997; Pufahl, 2010; Sanches, 2012).

Nas etapas desse processo, o mineral apatita sofre várias transformações. A apatita sedimentar (francolita) é um mineral autigênico que se desenvolve nos sedimentos, com baixa solubilidade. Devido ao tipo de ligações químicas que compõem a francolita, muitas substituições podem ocorrer nas ligações com $\mathrm{Ca}$ e nos sítios de $\mathrm{PO}_{4}^{3-}$ e $\mathrm{F}^{-}$(Jarvis et al., 1994). Quando ocorre excesso de $\mathrm{F}^{-}$na francolita, esta se transforma em fluorapatita, isto é, na terceira e quarta etapas do processo de fosfogênese. Essa transformação é decorrente da quantidade de $\mathrm{CO}_{3}{ }^{2-}$ que substitui $\mathrm{PO}_{4}^{3-}$ no grupo tetraédrico $\left(\mathrm{CO}_{3}+\mathrm{F}\right)^{3-}($ McClellan e Kauwenbergh, 1990). Além disso, a precipitação dos sulfetos de ferro e/ou oxi-hidróxidos insolúveis provoca enriquecimento em elementos-traço que reflete condições de deposição e diagênese inicial, isto é, paleoprodutividade e paleoredox (Jarvis et al., 1994). Por isso ocorre enriquecimento no elemento-traço $\mathrm{U}$, aparecendo uma anomalia geofísica dentro da gamaespectrometria U-Th-K (e.g. Fianco et al., 2014; ver anomalia geofísica na Figura 1).

Além do interesse econômico nessas sucessões, a proliferação de depósitos de fosfato sedimentar durante o Neoproterozoico tem significado paleoambiental muito importante na história da Terra (Pufahl e Hiatt, 2012). A Era Neoproterozoica, conhecida por ser o "Bilhão Gelado" devido às imensas glaciações, algumas de caráter global, como prediz a teoria do Snowball Earth, evolui progressivamente para o Evento de Oxidação Neoproterozoica, culminando nos grandes depósitos de fosfato sedimentar que ocorrem associados ao evento de explosão de vida (e.g. Zhang et al., 2019). 


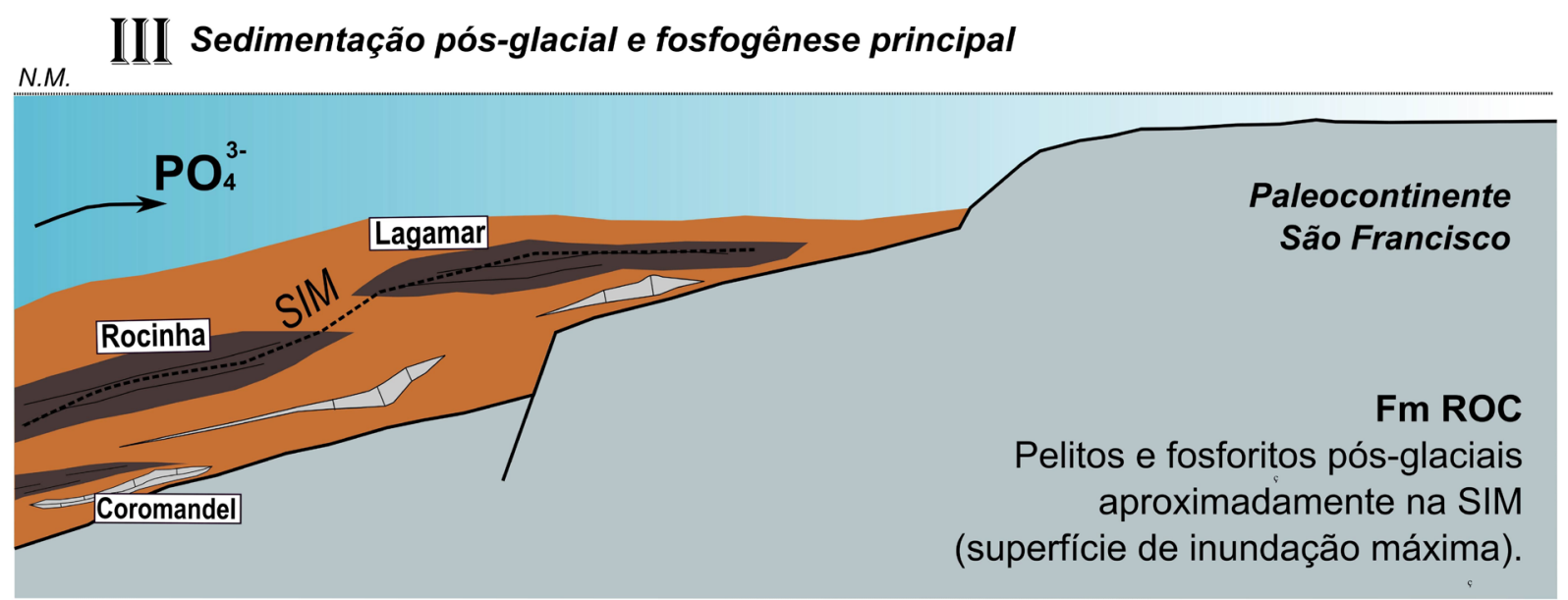

II Sedimentação sin- a pós-glacial e fosfogênese inicial
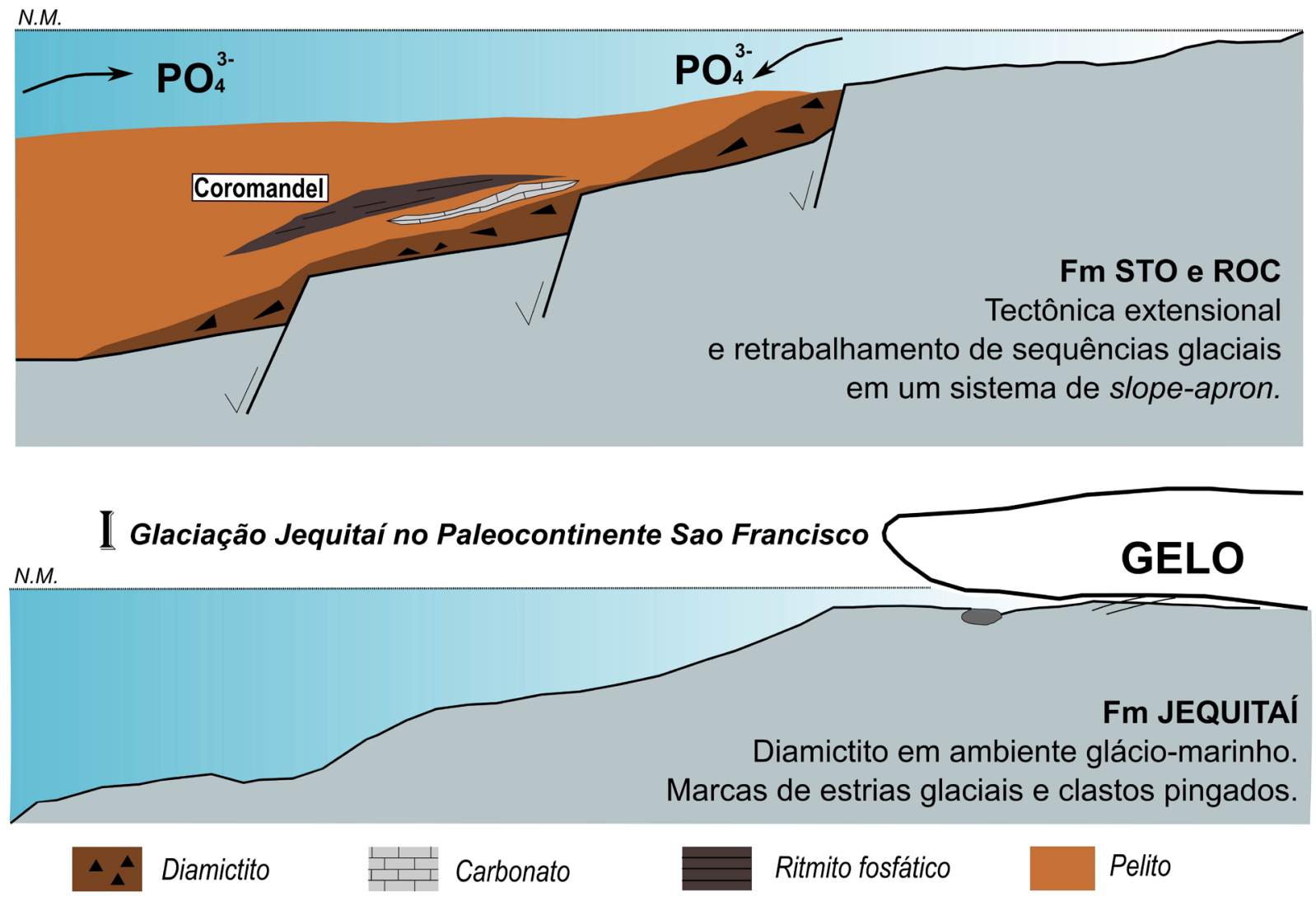

Fm: Formação; STO: Santo Antônio do Bonito; ROC: Rocinha.

Figura 10. Modelo evolutivo das Formações Jequitaí, Santo Antônio do Bonito e Rocinha ao longo do Neoproterozoico e relação com os depósitos de fosfato sedimentar.

Um número expressivo de depósitos fosfáticos pós-glaciais tem sido identificados em rochas marinhas neoproterozoicas depositadas em todos os continentes, algumas com acúmulo anômalo de fósforo (ver exemplos em Pufahl e Hiatt,
2012 e Pufahl e Groat, 2017). As altas concentrações de fosfato seriam resultado do intemperismo químico de rochas de fontes continentais, associado com a intensa erosão e o transporte glacial, bem como com condições deposicionais 
propícias provocadas pela presença da geleira (Cook, 1992). A variação eustática, isto é, a elevação do nível do mar na deglaciação, influencia diretamente a circulação do fósforo solúvel, não havendo similares em outros períodos geológicos (Cook, 1992; Boggiani, 2010). Assim, entender a cronologia dos eventos glaciação-fosfogênese é fundamental para o entendimento do ciclo do fósforo e da evolução da biota até o surgimento dos organismos macroscópicos no Ediacarano (Planavsky et al., 2010).

Os estudos geocronológicos e isotópicos apresentados neste trabalho sugerem idade ediacarana para os fosforitos do Grupo Vazante, uma vez que são correlacionados a rochas da base do Grupo Bambuí. Além disso, documentam estreita associação entre uma sucessão neoproterozoica pós-glacial e um evento de fosfogênese possivelmente associado às maiores concentrações de oxigênio atmosférico e oceânico reconhecidas para o final do Neoproterozoico. Assim sendo, os depósitos de fosfato sedimentar das formações basais do Grupo Vazante compõem um marco estratigráfico nas sucessões que cobrem o Cráton do São Francisco, correlacionável a outros depósitos de fosfato sedimentar pós-glaciais regionais (e.g. Monteiro, 2009; Drummond et al., 2015; Caird et al., 2017).

\section{CONCLUSÃO}

Na porção sul do Grupo Vazante, entre Coromandel e Lagamar, as Formações Santo Antônio do Bonito e Rocinha apresentam diamictitos, arenitos, siltitos, ritmitos, fosforitos e raros carbonatos. Constituem fácies sedimentares depositadas a partir de fluxos gravitacionais subaquosos (avalanches e correntes de turbidez), com predomínio de fácies grossas na base e de fácies pelíticas no topo, mostrando interdigitação lateral e vertical de fácies, passando de registros proximais (diamictitos) para distais (pelitos). Essas fácies compõem um sistema deposicional de slope-apron, na transição entre a Faixa Brasília e o Cráton do São Francisco.

A similaridade dos registros faciológicos, estratigráficos, geocronológicos $(\mathrm{U}-\mathrm{Pb})$ e isotópicos $(\mathrm{Sm}-\mathrm{Nd})$ entre as Formações Santo Antônio do Bonito, Rocinha e Jequitaí sugere correlação lateral. As três amostras com dados geocronológicos pelo método U-Pb em zircão detrítico do Grupo Vazante têm idade deposicional máxima de $934 \pm 8 \mathrm{Ma}$ (idade concordante mais jovem) e proveniência semelhante, com fontes de zircões do Paleoproterozoico (principalmente Riaciano e Orosiano) a Mesoproterozoico (Calimiano e Ectasiano), oriundas do paleocontinente São Francisco. Dados isotópicos $\mathrm{Sm}-\mathrm{Nd}$, apresentados neste trabalho, corroboram as interpretações estratigráficas e geocronológicas. Os dados
Sm-Nd mostram, também, grande semelhança entre as Formações Santo Antônio do Bonito e Jequitaí, cujas idades $T_{D M}$ são Paleoproterozoicas, com valores entre 1,8 e 2,1 Ga. Além disso, os dados geocronológicos e isotópicos $(\mathrm{Sm}-\mathrm{Nd})$ mostram grande diferença entre a Formação Rocinha e o Grupo Bambuí, em especial com a Formação Serra de Santa Helena. Comparando-se as unidades basais do Grupo Vazante, nota-se que a Formação Rocinha apresenta predomínio de fácies pelíticas, maior quantidade de grãos de zircões neoproterozoicos e idades $\mathrm{T}_{\mathrm{DM}}$ mais jovens do que a Formação Santo Antônio do Bonito, possivelmente devido à sedimentação retrogradacional pós-glacial.

Ocorreu, sobre o paleocontinente São Francisco, uma glaciação global, relacionada, provavelmente, ao evento Marinoano, do final do Criogeniano, registrada pela Formação Jequitaí. Lateralmente, para oeste, em direção à margem passiva da Faixa Brasília, os sedimentos glaciais marinhos foram retrabalhados por sedimentação gravitacional, em um sistema deposicional de cunhas clásticas subaquosas, um tipo de leque submarino, associado, provavelmente, a uma tectônica extensional (Formações Santo Antônio do Bonito e Rocinha).

O depósito fosfático de Coromandel (Fosforito 1) ocorre próximo aos diamictitos, provavelmente a partir de fósforo proveniente do continente, em parte sincrônico ao evento glacial. Por sua vez, os depósitos Rocinha (Fosforito 2) e Lagamar (Fosforito 3) são contemporâneos e estratigraficamente acima do Fosforito 1 , tendo se depositado em uma provável superfície de inundação máxima, na transgressão pós-glacial. Ritmitos com níveis fosfoareníticos enriquecidos em intraclastos fosfáticos são importantes e mostram condições de retrabalhamento por correntes marinhas a partir de depósitos fosfáticos primários. Os depósitos de fosfato sedimentar instalaram-se, de forma geral, durante evento transgressivo, após o evento glacial, coincidente com o Evento de Oxidação Neoproterozoica, no Período Ediacarano.

\section{AGRADECIMENTOS}

À Coordenação de Aperfeiçoamento de Pessoal de Nível Superior (CAPES), pela bolsa de doutorado da primeira autora, e ao Centro de Pesquisa Manuel Teixeira da Costa (CPMTC-UFMG), pelos suportes logístico e técnico. As análises isotópicas foram realizadas com o financiamento dos projetos pelo Conselho Nacional de Desenvolvimento Científico e Tecnológico (CNPq), Processo $n^{\circ}$ 447449/2014-1, e pela Fundação de Amparo à Pesquisa de Minas Gerais (FAPEMIG), Processo $n^{\circ}$ CRA - APQ 01711-14. 


\section{REFERÊNCIAS}

Alkmim, F. F. (2004). O que faz de um craton um cráton? O Cráton do São Francisco e as revelações almeidianas ao delimitá-lo. In: V. Mantesso-Neto, A. Bartorelli, C. D. R. Carneiro, B. B. Brito-Neves (Eds.). Geologia do Continente Sul Americano: Evolução da obra de Fernando Flávio Marques de Almeida (p. 16-36). São Paulo: Beca.

Alkmim, F. F., Martins-Neto, M. A. (2001). A bacia intracratônica do São Francisco: arcabouço estrutural e cenários evolutivos. In: C. P. Pinto, M. A. Martins-Neto (Eds.). A Bacia do São Francisco: Geologia e recursos naturais (p. 9-30). Belo Horizonte: SBG.

Alvarenga, C. J. S., Oliveira, G. D., Vieira, L. C., Santos, R. V., Baptista, M. C., Dantas, E. L. (2019). Carbonate chemostratigraphy of the Vazante Group, Brazil: a probable Tonian age. Precambrian Research, 331, 105378. https://doi.org/10.1016/j.precamres.2019.105378

Alvarenga, C. J. S., Santos, R. V., Vieira, L. C., Lima, B. A. F., Mancini, L. H. (2014). MesoNeoproterozoic isotope stratigraphy on carbonates platforms in the Brasília Belt of Brazil. Precambrian Research, 251, 164-180. https://doi.org/10.1016/j. precamres.2014.06.011

Arnott, R. W. C. (2010). Deep-Marine sediments and Sedimentary Systems. In: N. P. James and R. W. Dalrymple (Eds.). Facies Models 4 (p. 295-322). Canadá: Geological Association of Canada.

Azmy, K., Kendall, B., Creaser, R. A., Heaman, L., Oliveira, T. F. (2008). Global correlation of the Vazante Group, São Francisco Basin, Brazil: Re-Os and $\mathrm{U}-\mathrm{Pb}$ radiometric age constraints. Precambrian Research, 164(3-4), 160-172. https://doi.org/10.1016/j. precamres.2008.05.001

Babinski, M., Vieira, L. C., Trindade, R. I. F. (2007). Direct dating of Sete Lagoas cap carbonate (Bambuí Group, Brazil) and implications for the Neoproterozoic glacial events. Terra Nova, 19(6), 401-406. https://doi. org/10.1111/j.1365-3121.2007.00764.x

Boggiani, P. C. (2010). Sedimentação autigênica neoproteorozoica e mineralizações associadas - um registro não uniformitarista. Tese (Livre-Docência). São Paulo: IGc - Universidade de São Paulo, 137 p. https:// doi.org/10.11606/T.44.2015.tde-07082015-135343
Boggs, S. (2006). Principles of Sedimentology and Stratigraphy. Califórnia: Pearson Prentice Hall, 662 p. Disponível em: http://www.science.earthjay.com/instruction/ HSU/2015_fall/GEOL_332/SedimentologyStratigraphy4e. pdf. Acesso em: 20 maio 2021.

Boujo, A., Trompette, R., Flicoteaux, R., Melfi, A. J., Affaton, P., Bloy, A., Monteiro, M. D., Oliveira, J. J., Magat, P. (1994). Fosfatos sedimentares marinhos de proterozoico médio e superior e do cambriano da Africa e do Brasil: geologia, mineralogia, geoquímica e importância econômica. Anais da Academia Brasileira de Ciências, 66(3), 293-318. Disponível em: https:// horizon.documentation.ird.fr/exl-doc/pleins_textes/ pleins_textes_6/b_fdi_35-36/41850.pdf. Acesso em: 20 maio 2021 .

Caird, R. A., Pufahl, P. K., Hiatt, E. E., Abram, M. B., Rocha, A. J. D., Kyser, T. K. (2017). Ediacaran stromatolites and intertidal phosphorite of the Salitre Formation, Brazil: Phosphogenesis during the Neoproterozoic Oxygenation Event. Sedimentary Geology, 350, 55-71. https://doi.org/10.1016/j. sedgeo.2017.01.005

Campos-Neto, M. C. (1984). Litostratigrafia e evolução paleogeográfica dos Grupos Canastra e Paranoá (Região Vazante-Lagamar, MG). Revista Brasileira de Geociências, 14(2), 81-91. https://doi. org/10.25249/0375-7536.19848191

Carvalho, M. O., Valeriano, C. M., Aguiar Neto, C. C., Oliveira, G. D., Heilbron, M. (2019). The Vazante and Canastra groups revisited: $\mathrm{Sm}-\mathrm{Nd}$ and $\mathrm{Sr}$ isotopes - evidence for contribution from Tonian intraplate magmatism during passive margin development along the SW São Francisco margin, Brazil. Brazilian Journal Geology, 49(1), e20180081. https://doi. org/10.1590/2317-4889201920180081

Caxito, F. A., Halverson, G. P., Uhlein, A., Stevenson, R., Dias, T. G., Uhlein, G. J. (2012). Marinoan glaciation in east Central Brazil. Precambrian Research, 200-203, 38-58. https://doi.org/10.1016/j.precamres.2012.01.005

Companhia de Pesquisa de Recursos Minerais (CPRM). (1976). Projeto Patos de Minas: relatório final de pesquisa. Belo Horizonte: CPRM. v. 2, 78 p.

Companhia de Pesquisa de Recursos Minerais (CPRM). (1979). Projeto Coromandel CPRM. Boletim de Sondagens e Análises, v. 2, 166 p. 
Cook, P. J. (1992). Phosphogenesis around the ProterozoicPhanerozoic transition. Journal of the Geological Society, 149(4), 615-620. https://doi.org/10.1144/gsjgs.149.4.0615

Cukrov, N., Alvarenga, C. J. S., Uhlein, A. (2005). Litofácies de glaciação neoproterozoica nas porções sul do Cráton do São Francisco: exemplos de Jequitaí (MG) e Cristalina (GO). Revista Brasileira de Geociências, 35(1), 69-76. https://doi.org/10.25249/0375-7536.20053516976

Dalrymple, R. W. (2010). Interpreting sedimentary successions: facies, facies analysis and facies models. In: N. P. James \& R. W. Dalrymple (Eds.) Facies Models 4 (p. 3-18). Canadá: Geological Association of Canada. Geotext 6 .

Dardenne, M. A. (1978). Síntese sobre a estratigrafia do Grupo Bambuí no Brasil Central. XXX Congresso Brasileiro de Geologia, v. 2, p. 597-610. Recife: SBG.

Dardenne, M. A. (2000). The Brasília fold belt. In: U. G. Cordani, E. J. Milani, A. Thomaz Filho, D. A. Campos (Eds.) Tectonic Evolution of South América (p. 231-264). Rio de Janeiro. Disponível em: http://rigeo.cprm.gov. br/jspui/handle/doc/19419. Acesso em: 20 maio 2021.

Dardenne, M. A. (2001). Lithostratigraphic sedimentary sequences of the Vazante Group. In: A. Misi and J. B. G. Teixeira (eds.). Proterozoic Base Metal Deposits of Africa and South America, IGCP 450. 1st Field Workshop, Belo Horizonte and Paracatu. p. 48-50.

Dardenne, M. A., Freitas-Silva, F. H., Nogueira, G. M. S., Souza, J. F. C. (1997). Depósitos de fosfato de Rocinha e Lagamar, Minas Gerais. In: C. Schobbenhaus, E. T. Queiroz, C. E. S. Coelho (Coords.) Principais Depósitos Minerais do Brasil (v. 4C, p. 113-122). DNPM-CPRM.

Dardenne, M. A., Freitas-Silva, F. H., Souza, J. C. F., Campos, J. E. G. (1998). Evolução tectonosedimentar do Grupo Vazante no contexto da Faixa de Dobramentos Brasília. XL Congresso Brasileiro de Geologia, p. 26. Belo Horizonte: SBG.

Dardenne, M. A., Trompette, R., Magalhães, R. F., Soares, L. A. (1986). Proterozoic and Cambrian phosphorites - regional review: Brazil. In: P. J. Cook and J. H. Shergold (eds.). Proterozoic and Cambrian Phosphorites (p. 116-131). Cambridge: Cambridge University Press. Disponível em: https://www.researchgate.net/ publication/263659058_Proterozoic_and_Cambrian_ Phosphorites_Specialist_Studies_Early_Cambrian_ palaeogeogaphy_palaeoceanography_and_phosphorites. Acesso em: 20 maio 2021.

DePaolo, D. J. (1988). Neodymium Isotope Geochemistry: An Introduction. Heidelberg: Springer-Verlag, 187 p. https://doi.org/10.1007/978-3-642-48916-7

Drummond, J. B. R., Pufahl, P. K., Porto, C. G., Carvalho, M. (2015). Neoproterozoic peritidal phosphorite from the Sete Lagoas Formation (Brazil) and the Precambrian phosphorus cycle. Sedimentology, 62(7), 1978-2008. https://doi.org/10.1111/sed.12214

Fernandes, A. F. (2013). Tectonoestratigrafia da Faixa Brasília Meridional e Estudo de Casos de Possíveis Rochas Fonte de Diamante, Coromandel-MG. Dissertação (Mestrado). Belo Horizonte: Instituto de Geociências, Universidade Federal de Minas Gerais, 119 p.

Fianco, C. B., Vidotti, R. M., Pires, A. C. B. (2014). Phosphorite prospection using ground gamma spectrometry in northeast Goiás State, Brazil. Revista Brasileira de Geofísica, 32(4), 1-13. https://doi.org/10.22564/rbgf. v32i 4.540

Föllmi, K. B. (1996). The phosphorus cycle, phosphogenesis and marine phosphate-rich deposits. Earth-Science Reviews, 40(1-2), 55-124. https://doi. org/10.1016/0012-8252(95)00049-6

Fuck, R. A., Jardim de Sá, E. F., Pimentel, M. M., Dardenne, M. A., Pedrosa-Soares, A. C. (1993). As faixas de dobramentos marginais do Cráton do São Francisco. In: J. M. L. Dominguez e A. Misi (eds.). O Cráton do São Francisco (p. 161-185). Salvador: SBG/SGM/CNPq.

Geboy, N. J., Kaufman, A. J., Walker, R. J., Misi, A., Oliveira, T. F., Miller, K. E., Azmy, K., Kendall, B., Poulton, S. W. (2013). Re-Os age constraints and new observations of Proterozoic glacial deposits in the Vazante Group, Brazil. Precambrian Research, 238, 199-213. https://doi.org/10.1016/j.precamres.2013.10.010

Jarvis, I., Burnett, W. C., Nathan, Y., Almbaydin, F. S. M., Attia, A. K. M., Castro, L. N., Flicoteaux, R., Hilmy, M. E., Husain, V., Qutawnnah, A. A., Serjani, A., Zanin, Y. N., (1994). Phosphorite geochemistry: state of the art and environmental concerns. Eclogae Geologicae Helvetiae, 87(3), 643-700. Disponível em: https://www. researchgate.net/publication/279905385_Phosphorite_ geochemistry_state-of-the-art_and_environmental_ concerns. Acesso em: 20 maio 2021. 
Karfunkel, J., Hoppe, A. (1988). Late Proterozoic glaciation in central-eastern Brazil: synthesis and model. Palaeogeoggrphy, Palaeoclimatology, Palaeoecology, 65(1-2), 1-21. https://doi. org/10.1016/0031-0182(88)90108-3

Kazakov, A. V. (1937). The phosphorite facies and the genesis of phosphorites. In: B. M. Himmelfarb, A. V. Kazakov, I. M. Kurman (eds.). Geological Investigations of Agricultural Ores (p. 95-113). Moscou: Tr. NIUIF.

Kuchenbecker, M., Babinski, M., Pedrosa-Soares, A. C., Lopes-Silva, L., Pimenta, F., (2016). Chemostratigraphy of the lower Bambuí Group, southwestern São Francisco Craton, Brazil: insights on Gondwana paleoenvironments. Brazilian Journal of Geology, 46(1), 145-162. https:// doi.org/10.1590/2317-488920160030285

Lima, O. N. B., Uhlein, A., Britto, W. (2007). Estratigrafia do Grupo Bambuí na Serra da Saudade e geologia do depósito fosfático de Cedro do Abaeté, Minas Gerais. Revista Brasileira de Geociências, 37(4-supl.), 204-215. https://doi.org/10.25249/0375-7536.200737S4204215

Lowe, D. R. (1982). Sedimentary gravity flows: II Depositional models with special reference to deposits of high-density turbidity currents. Journal of Sedimentary Petrology, 52(1), 279-297. https://doi. org/10.1306/212F7F31-2B24-11D7-8648000102C1865D

Marques, C. S. S. (2019). A porção sul do Grupo Vazante entre Lagamar e Coromandel (MG): estratigrafia, geocronologia e fosfogênese neoproterozoica. Tese (Doutorado). Belo Horizonte: Universidade Federal de Minas Gerais, Instituto de Geociências, 117 p.

Marques, C. S. S., Uhlein, A., Oliveira, G. D., Uhlein, G. J., Sial, A. N., Alvarenga, C. J. S. (2015). Geologia e quimioestratigrafia isotópica do Grupo Vazante em Lagamar (MG). Geonomos, 23(1), 26-41. https://doi. org/10.18285/geonomos.v23i1.659

Marques, C. S. S., Uhlein, A., Uhlein, G. J. (2021). Stratigraphy and $\mathrm{U}-\mathrm{Pb}$ Geochronology of the basal units of the Vazante Group: a lateral correlation to the glaciogenic Jequitaí Formation (Minas Gerais, Brazil). Journal of South American Earth Sciences, 108, 103204. https://doi.org/10.1016/j.jsames.2021.103204

Marques, C. S. S., Uhlein, A., Uhlein, G. J., Oliveira, G. D., Sial, A. N., Alvarenga, C. J. C. (2019). Associação de Fácies, Litoquímica e Geologia Isotópica da Formação Lagamar (Grupo Vazante, Minas Gerais): uma
Plataforma Carbonática no Mesoproterozoico. Anuário do Instituto de Geociências, 42(4), 71-82. https://doi. org/10.11137/2019_4_71_82

Martins-Ferreira, M. A. C., Campos, J. E. G., Alvarenga, C. J. S. (2013). A Formação Jequitaí na região de Vila Boa, GO: exemplo de sedimentação por geleiras terminais no Neoproterozoico. Brazilian Journal of Geology, 43(2), 373-384. https://doi.org/10.5327/ Z2317-48892013000200012

McClellan, G. H., Kauwenberg, S. J. (1990). Mineralogy of sedimentary apatites. In: A. J. G. Notholt and I. Jarvis (eds.). Phosphorite research and development (v. 52, p. 23-31). Londres: Geological Society, Special Publications. https://doi.org/10.1144/GSL.SP.1990.052.01.03

McLennan, S. B. (1989). Rare earth elements in sedimentary rocks: influence of provenance and sedimentary processes. In: B. Lipin, G. McKay (Eds.). Geochemistry and Mineralogy of the Rare Earth Elements (p. 169-200). Mineralogical Society of America. https:// doi.org/10.1515/9781501509032-010

Misi, A. (2001). Estratigrafia Isotópica das Seqüências do Supergrupo São Francisco, Coberturas Neoproterozoicas do Crtaon do São Francisco: Idade e Correlações. In: C. P. Pinto e M. A. Martins Neto (Eds.). Bacia do São Francisco, Geologia e Recursos Naturais (v. 1, p. 67-92). Belo Horizonte: Sociedade Brasileira de Geologia, Núcleo de Minas Gerais.

Misi, A., Azmy, K., Kaufman, A. J., Oliveira, T. F., Sanches, A. L., Oliveira, G. D. (2014). Review of the geological and geochronological framework of the Vazante sequence, Minas Gerais, Brazil: Implications to metallogenic and phosphogenic models. Ore Geology Reviews, 63, 76-90. https://doi.org/10.1016/j. oregeorev.2014.05.002

Misi, A., Kaufman, A. J., Azmy, K., Dardenne, M. A., Sial, A. N., Oliveira, T. F. (2011). Neoproterozoic successions of the Sao Francisco craton, Brazil: the Bambuí, Una, Vazante and Vaza Barris/Miaba groups and their glaciogenic deposits. Geological Society of London, Memoirs, 36, 509-522. https://doi.org/10.1144/ M36.48

Monteiro, C. F. (2009). Fosforitos do Grupo Bambuí na região de Campos Belos (GO)/Arraias (TO), na borda oeste do Cráton São Francisco. Dissertação (Mestrado). Brasília: Instituto de Geociências, Universidade de Brasília. 
Moreira, D. S, Uhlein, A., Dussin, I. A., Uhlein, G. J., Misuzaki, A. M. P. (2020). A Cambrian Age for the Upper Bambuí Group, Brazil, supported by the first U-Pb dating of volcaniclastic bed. Journal of South American Earth Sciences, 99, 102503. https://doi.org/10.1016/j. jsames.2020.102503

Mourão, M. A. A. (1995). A unidade fosfática da Formação Sopa-Brumadinho, Supergrupo Espinhaço (região de Conceição do Mato Dentro, Minas Gerais): petrografia, geoquímica e considerações genéticas. Dissertação (Mestrado). Brasília: Instituto de Geociências, Universidade de Brasília, 124 p.

Nelson, G. J., Pufahl, P. K., Hiatt, E. E. (2010). Paleoceanographic constraints on Precambrian phosphorite accumulation, Baraga Group, Michigan, USA. Sedimentary Geology, 226(1-4), 9-21. https://doi. org/10.1016/j.sedgeo.2010.02.001

Nogueira, G. M. S. (1993). Enquadramento estratigráfico, sedimentologia e evolução geoquímica do depósito fosfático de Lagamar, MG - Formação Vazante Proterozóico Médio. Dissertação (Mestrado). Brasília: Instituto de Geociências, Universidade de Brasília, 134 p.

Okubo, J., Muscente, A., Luvizotto, G. L., Uhlein, G. J., Warren, L. (2018). Phosphogenesis, aragonite fan formation and seafloor environments following the Marinoan glaciation. Precambrian Research, 311, 24-36. https://doi.org/10.1016/j.precamres.2018.04.002

Oliveira, G. D. (2013). Reconstrução Paleoambiental e Quimioestratigrafia dos Carbonatos Hospedeiros do depósito de Zinco Silicatado de Vazante, $M G$. Dissertação (Mestrado). Brasília: Instituto de Geociências, Universidade de Brasília, 95 p.

Pimentel, M. M., Rodrigues, J. B., Della Giustina, M. E. S, Junges, S., Matteini, M., Armstrong, R. (2011). The tectonic evolution of the Neoproterozoic Brasília Belt, central Brazil, based on SHRIMP and LA-ICPMS $\mathrm{U}-\mathrm{Pb}$ sedimentary provenance data: A review. Journal of South American Earth Sciences, 31(4), 345-357. https:// doi.org/10.1016/j.jsames.2011.02.011

Pinho, J. M. M., Féboli, W. L., Signorelli, N., Tuller, M. P., Brito, D. C., Ribeiro, J. H., Baptista, M. C., Silva, R. N. (2017). Geologia e Recursos Minerais das Folhas Cabeceira Grande, Unai, Ribeirão Arrojado, Serra da Aldeia, Serra da Tiririca, Paracatu, Guarda-Mor, Arrenegado, Coromandel, Lagamar, Monte Carmelo, Patos de Minas. Projeto Vazante-Paracatu, Estado de
Minas Gerais e Goiás: texto explicativo. Belo Horizonte: CPRM - Programa Geologia Brasil, 356 p.

Planavsky, N. J., Rouxel, O. J., Bekker, A., Lalonde, S. V., Konhauser, K. O., Reinhard, C. T., Lyons, T. W. (2010). The evolution of the marine phosphate reservoir. Nature, 467, 1088-1090. https://doi.org/10.1038/nature09485

Pufahl, P. K. (2010). Bioelemental Sediments - Chapter 20. In: N. P. James and R. W. Dalrymple (Eds.). Facies models 4 (p. 477-503). Canadá: Geological Association of Canada.

Pufahl, P. K., Abram, M. B., Moraes Filho, J. C., Brilhante, J. R., Porto, C. G., Pinho, J. M. M. (2016). Correlação preliminar de rochas sedimentares fosfáticas do Grupo Bambuí, Bacia do São Francisco, nas regiões de Campos Belos nos Estados de Tocantins/Goiás e Lagamar, em Minas Gerais. In: M. B. Abram, I. A. Cunha, R. C. Almeida (Eds.). Projeto Fosfato Brasil - Parte II (p. 606-620). CPRM.

Pufahl, P. K., Groat, L. A. (2017). Sedimentary and Igneous Phosphate Deposits: Formation and Exploration: An Invited Paper. Economic Geology, 112(3), 483-516. https://doi.org/10.2113/econgeo.112.3.483

Pufahl, P. K., Hiatt, E. E. (2012). Oxygenation of the Earth's atmosphere-ocean system: a review of physical and chemical sedimentologic responses. Marine and Petroleum Geology, 32(1), 1-20. https://doi.org/10.1016/j. marpetgeo.2011.12.002

Rocha-Araújo, P. R., Flicoteaux, R., Parron, C., Trompette, R. (1992). Phosphorites of Rocinha mine; Patos de Minas (Minas Gerais, Brazil): genesis and evolution of a middle Proterozoic deposit tectonized by Brasiliano Orogeny. Economic Geology, 87(2), 332-351. https:// doi.org/10.2113/gsecongeo.87.2.332

Rodrigues, J. B. (2008). Proveniência de sedimentos dos grupos Canastra, Ibiá, Vazante e Bambuí - Um estudo de zircões detríticos e Idades Modelo Sm-Nd. Tese (Doutorado). Brasília: Universidade de Brasília, $128 \mathrm{p}$.

Rodrigues, J. B., Pimentel, M. M., Buhn, B., Matteini, M., Dardenne, M. A., Alvarenga, C. J. S., Armstrong, R. A. (2012). Provenance of the Vazante Group: New $\mathrm{U}-\mathrm{Pb}, \mathrm{Sm}-\mathrm{Nd}$, Lu-Hf isotopic data and implications for the tectonic evolution of the Neoproterozoic Brasília Belt. Gondwana Research, 21(2-3), 439-450. https:// doi.org/10.1016/j.gr.2011.07.017 
Sanches, A. L. (2012). Fosforitos Neoproterozóicos dos Grupos Vazante (MG) e Una (BA): Origem, Idades e Correlações. Tese (Doutorado). Salvador: Universidade Federal da Bahia, 158 p.

Shanmugam, G. (2000). 50 years of the turbidite paradigm (1950s - 1990s: deep water process and facies models - a critical pespective. Marine and Petroleum Geology, 17(2), 285-342. https://doi.org/10.1016/S0264-8172(99)00011-2

Sotero, M. P., Caxito, F. A., Dias, P. H. A., Sotero, B. A. (2019). Análise de fácies e ambientes deposicionais do Grupo Vazante na região da mina de Morro Agudo, Paracatu, noroeste do estado de Minas Gerais. Geologia USP. Série Cientifica, 19(2), 195-214. https://doi. org/10.11606/issn.2316-9095.v19-144761

Souza, C. F. (1997). Litoestratigrafia e sedimentologia da Formação Vazante na região de Coromandel - MG. Dissertação (Mestrado). Brasília: Instituto de Geociências, Universidade de Brasília, 76 p.

Stow, D. A. V. (1985). Deep-sea clastics: where are we and where are we going? In: P. J. Brenchley and B. P. J. Williams. Sedimentology: recent developments and applied aspects (v. 18, p. 67-93). LondreS: Geological Society of London, Special Publication. https://doi. org/10.1144/GSL.SP.1985.018.01.05

Teles, L. S. B. (2019). Caracterização, gênese e correlação estratigráfica dos fosforitos da região de Coromandel - MG. Dissertação (Mestrado). Brasília: Instituto de Geociências, Universidade de Brasília, 92 p.

Uhlein, A., Alvarenga, C. J. S., Dardenne, M. A., Trompette, R. R. (2011). The glaciogenic Jequitaí Formation, southeastern Brazil. In: E. Arnaud, G. P. Halverson, G. Shields-Zhou. (Eds.). The Geological Record of Neoproterozoic Glaciations. Geological Society of London, London, Memoir, 36, 51-66. https:// doi.org/10.1144/M36.51

Uhlein, A., Marques, C. S. S., Uhlein, G. J. (2018). Fertilizantes provenientes de depósitos sedimentares de fosfato e de potássio pré-cambrianos. In: A. C. PedrosaSoares, E. Voll, E. C. Cunha (Coords.). Recursos Minerais de Minas Gerais On Line: Síntese do conhecimento sobre as riquezas minerais, história geológica, e meio ambiente e mineração de Minas Gerais. Belo Horizonte: Companhia de Desenvolvimento de Minas Gerais (CODEMGE). Disponível em: http://recursomineralmg. codemge.com.br/substancias-minerais/fertilizantesprovenientes-de-depositos-sedimentares-de-fosfato-epotassio-pre-cambrianos/\#. Acesso em: $1^{\circ}$ jul. 2021.

Uhlein, G. J., Uhlein, A., Halverson, G. P., Stevenson, R., Caxito, F. A., Cox, G. M., Carvalho, J. F. M. G. (2016). The Carrancas Formation, Bambuí Group: A record of pre-Marinoan sedimentation on the southern São Francisco craton, Brazil. Journal of South American Earth Sciences, 71, 1-16. https://doi.org/10.1016/j. jsames.2016.06.009

Uhlein, G. J., Uhlein, A., Stevenson, R., Halverson, G. P., Caxito, F. A., Cox, G. M. (2017). Early to late Ediacaran conglomeratic wedges from a complete foreland basin cycle in the southwest São Francisco Craton, Bambuí Group, Brazil. Precambrian Research, 299, 101-116. https://doi.org/10.1016/j.precamres.2017.07.020

Valeriano, C. M. (2017). The southern Brasília Belt. In: M. Heibron, U. G. Cordani, F. F. Alkmim (eds.), São Francisco Craton, Eastern Brazil (p. 189-203). Cham: Springer. https://doi.org/10.1007/978-3-319-01715-0_10

Valeriano, C. M., Dardenne, M. A., Fonseca, M. A., Simões, L. S. A., Seer, H. J. (2004). A evolução tectônica da Faixa Brasília. In: V. Mantesso Neto, A. Bartorelli, C. D. R. Carneiro, B. B. Brito Neves (Eds.), Geologia do continente Sul-Americano: Evolução da obra de Fernando Flávio Marques de Almeida (p. 575-592). São Paulo: Beca.

Walker, R. G. (1992). Turbidites and Subamarine fans. In: R. G. Walker and N. P. James (Eds.), Facies Models: Response to Sea Level Change (p. 239-275). Canadá: Geological Association of Canada.

Zhang, Y., Pufahl, P. K., Du, Y., Chen, G., Liu, J., Chen, Q., Wang, Z., Yu, W. (2019). Economic phosphorite from the Ediacaran Doushantuo Formation, South China, and the Neoproterozoic-Cambrian Phosphogenic Event. Sedimentary Geology, 388, 1-19. https://doi. org/10.1016/j.sedgeo.2019.05.004 
Anexo 1. Tabela de coordenadas dos pontos de amostragem Sm-Nd e U-Pb (UTM 23S WGS84).

\begin{tabular}{lcc}
\hline Ponto & E & W \\
\hline LA 304* & 306397 & 7984696 \\
LA 306* & 305466 & 7983626 \\
COR 21* & 287856 & 7953885 \\
COR 23* & 288993 & 7954139 \\
COR 03 & 291294 & 7952831 \\
RG 26* & 291491 & 7951653 \\
\hline Ponto & E & W \\
\hline SH 2 topo & 563576 & 7867245 \\
SH 2 base\# & 563576 & 7867245 \\
SH 3 topo & 569073 & 7850256 \\
SH 3 base\# & 569073 & 7850256 \\
JEQ 1 & 572869 & 8116717 \\
JEQ 2 & 558876 & 8096749 \\
RG01 & 288418 & 7954132 \\
RG51 & 287497 & 7954001 \\
\hline
\end{tabular}

